
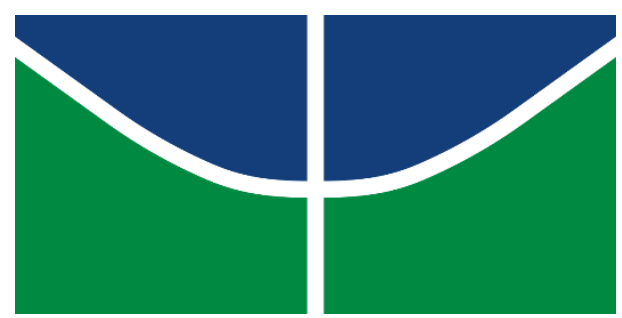

Universidade de Brasília (UnB)

Faculdade de Economia, Administração, Contabilidade e Gestão Pública (FACE)

Departamento de Ciências Contábeis e Atuariais (CCA)

Bacharelado em Ciências Contábeis

Marco Aurélio Barros Borges

GERENCIAMENTO DE RESULTADOS EM COOPERATIVAS DE CRÉDITO NO BRASIL 
Professora Doutora Márcia Abrahão Moura

Reitora da Universidade de Brasília

Professora Doutora Cláudia da Conceição Garcia

Decana de Ensino de Graduação

\section{Professora Doutora Helena Eri Shimizu}

Decana de Pós-graduação

Professor Doutor Eduardo Tadeu Vieira

Diretor da Faculdade de Economia, Administração e Contabilidade

Professor Doutor José Antônio de França

Chefe do Departamento de Ciências Contábeis e Atuariais

Professor Doutor César Augusto Tibúrcio Silva Coordenador do Programa Pós-graduação em Ciências Contábeis

Professor Doutor Paulo Augusto Pettenuzzo de Britto Coordenador de Graduação do curso de Ciências Contábeis - Diurno

Professor Mestre Elivânio Geraldo de Andrade Coordenador de Graduação do curso de Ciências Contábeis - Noturno 
Marco Aurélio Barros Borges

\section{GERENCIAMENTO DE RESULTADOS EM COOPERATIVAS DE CRÉDITO NO BRASIL}

Trabalho de Conclusão de Curso (Monografia) apresentado ao Departamento de Ciências Contábeis e Atuariais da Faculdade de Economia, Administração, Contabilidade e Gestão Pública da Universidade de Brasília como requisito à conclusão da disciplina Pesquisa em Ciências Contábeis e obtenção do grau de Bacharel em Ciências Contábeis.

Orientador:

Prof. José Alves Dantas

Linha de pesquisa:

Contabilidade e Mercado Financeiro

Área:

Contabilidade Financeira

Brasília, DF 


\section{BORGES, Marco Aurélio Barros}

Gerenciamento de Resultado em Cooperativas de Crédito no Brasil Marco Aurélio Barros Borges - Brasília, 2017. 51p.

Orientador(a): Prof. José Alves Dantas

Trabalho de Conclusão de curso (Monografia - Graduação) - Universidade de Brasília, 2 Semestre letivo de 2017.

Bibliografia.

1. Gerenciamento de Resultado 2. Cooperativas de Crédito 3. Provisão para créditos de liquidação duvidosa I. Departamento de Ciências Contábeis e Atuariais da Faculdade de Economia, Administração e Contabilidade da Universidade de Brasília. II. Título. 


\title{
GERENCIALMENTO DE RESULTADOS EM COOPERATIVAS DE CRÉDITO NO BRASIL
}

\begin{abstract}
Trabalho de Conclusão de Curso (Monografia) defendido e aprovado no Departamento de Ciências Contábeis e Atuariais da Faculdade de Economia, Administração, Contabilidade e Gestão Pública da Universidade de Brasília como requisito à conclusão da disciplina Pesquisa em Ciências Contábeis e obtenção do grau de Bacharel em Ciências Contábeis, aprovado pela seguinte comissão examinadora:
\end{abstract}

Prof. José Alves Dantas

Orientador

Departamento de Ciências Contábeis e Atuariais

Universidade Brasília (UnB)

Prof. Bruno Vinícius Ramos Fernandes

Examinador

Departamento de Ciências Contábeis e Atuariais

Universidade de Brasília (UnB)

Brasília, Novembro (2017) 
"Só se pode alcançar um grande êxito quando nos mantemos fiéis a nós mesmos." - Friedrich Nietzsche 


\section{AGRADECIMENTOS}

Agradeço primeiramente aos meus pais, Maria Cleide de Barros e Nelson Pereira Borges, por terem me ensinado o valor dos estudos na vida, sempre me motivando e acreditando na minha capacidade de alcançar meus objetivos de vida.

Ao meu irmão, Marcos Roberto Barros Borges, por não me deixar abater pelas dificuldades e acreditando em minha capacidade.

Aos meus amigos do Banco Cooperativo do Brasil, pela confiança depositada em mim nos ensinamentos diários para ser um bom profissional.

Ao meu Orientador, Professor Dr. José Alves Dantas, pelo privilégio de poder aprender e receber seus conselhos, não apenas no processo de construção da pesquisa, mas em sua aula aprendendo a gostar ainda mais da contabilidade.

Aos meus amigos, por fazerem parte do meu dia a dia, tornando-o sempre mais divertido.

Aos amigos que fiz na UnB, por compartilharem comigo momentos de alegria, tristeza e desespero. Que venham novos desafios!

A concretização deste grande desafio não seria possível se eu não tivesse pessoas surpreendentes com as quais pude contar. Muito obrigado a todos! 


\section{RESUMO}

O Gerenciamento de Resultados (GR) existe quando as normas contábeis permitem, a cargo dos gestores, um espaço para julgar o melhor método para apresentar a posição financeira. A literatura mostra que a administração das instituições financeiras tem utilizado sua discricionariedade na constituição de provisões sobre operações de crédito visando suavizar o resultado. Este estudo objetiva analisar se há utilização da conta de Provisões com Créditos de Liquidação Duvidosa (PCLD) como ferramenta de gerenciamento de resultados nas instituições financeiras cooperativas atuantes no Brasil. Para alcançar os objetivos do estudo, a presente pesquisa trabalha com dados em painel não balanceados, nos quais são analisadas as 500 maiores cooperativas de crédito classificas por ativos totais no relatório IF.data do Banco Central do Brasil (BCB), considerando a data-base de junho de 2017. Delimitou-se como período analisado as informações trimestrais de março de 2013 a junho de 2017. De maneira geral, os resultados mostram que há associação positiva e estaticamente relevante entre a PCLD discricionária e o lucro líquido ajustado. O modelo demonstrou ainda que outras variáveis de controle, tais como a variação do estoque das operações de crédito, o PIB do país, a variação negativa do resultado e o prejuízo da cooperativa de crédito em dado período, influenciam o comportamento da margem discricionária dessa provisão. Com isso, aponta-se que os gestores procuram suavizar os resultados nas instituições financeiras cooperativas com a utilização da parcela arbitrária da PCLD.

Palavras-chave: Gerenciamento de Resultados; Cooperativas de Crédito; Provisão para Créditos de Liquidação Duvidosa; Discricionariedade; Instituições Financeiras 


\begin{abstract}
Earning Management exists when accounting standards allow managers to allocate a space to judge the best method to present the financial position. The literature shows that the management of financial institutions have used their discretion in the constitution of provisions on credit operations in order to soften the result. This study aims to analyze if there is use of the Allowance for Allowance for Loan Losses as a tool for managing results in cooperative financial institutions operating in Brazil. In order to reach the objectives of the study, the present research works with unbalanced panel data, in which the 500 largest credit cooperatives classified by total assets are analyzed in the IF.data report of the Central Bank of Brazil (BCB) June 2017. The quarterly information for the period from March 2013 to June 2017 was delimited. In general, the results show that there is a positive and statistically significant association between the discretionary provision and the adjusted net income. The model also demonstrated that other control variables, such as the variation of the stock of credit operations, the product of the country's economy, the negative variation of the result and the credit union's loss in a given period, influence the behavior of the discretionary margin of this provision. Thus, it is pointed out that managers seek to soften the results in cooperative financial institutions by using the arbitrary portion of the Allowance for Loan Losses.
\end{abstract}

Keywords: Earning Management; Credit Union; Loan Loss Provisions; Discretionary Accruals; Financial Institution; 


\section{SUMÁRIO}

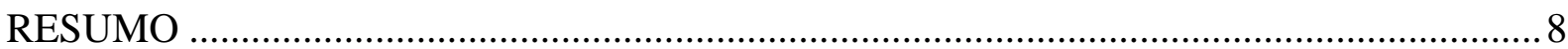

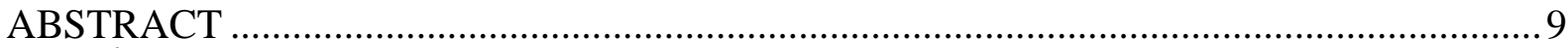

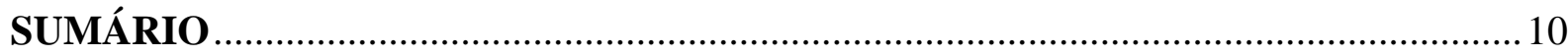

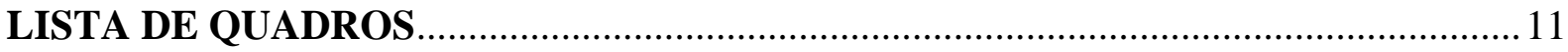

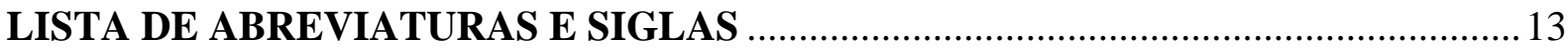

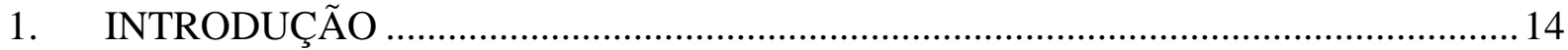

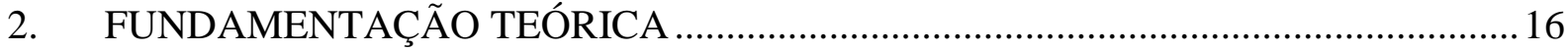

2.1. Sistema Nacional de Crédito Cooperativo (SNCC) ................................................. 16

2.2. Provisão para Créditos de Liquidação Duvidosa (PCLD) ....................................... 18

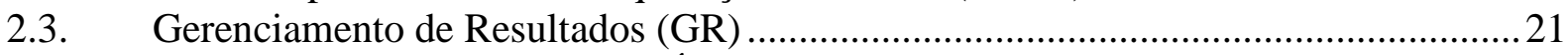

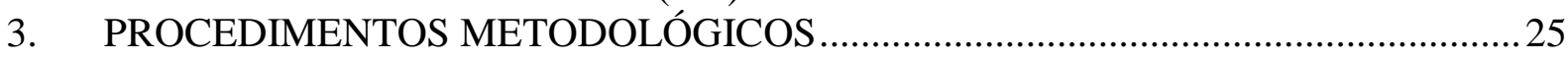

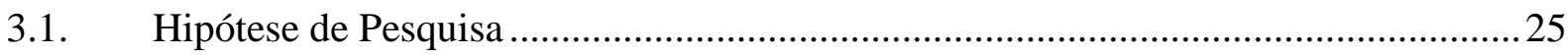

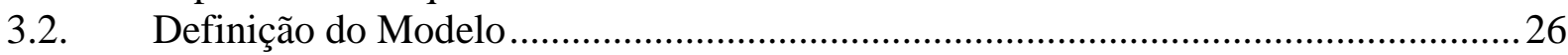

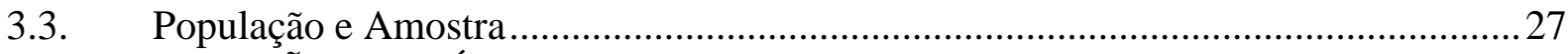

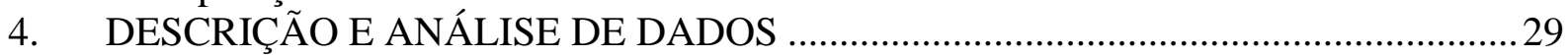

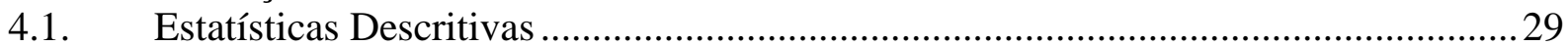

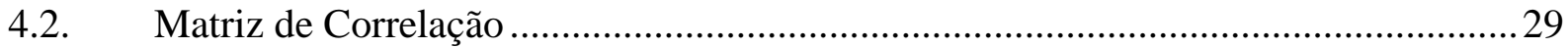

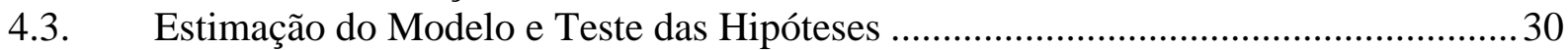

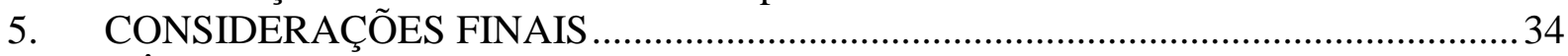

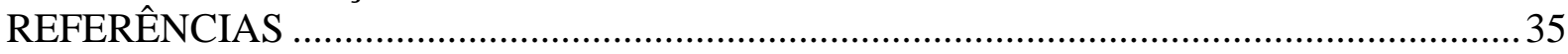

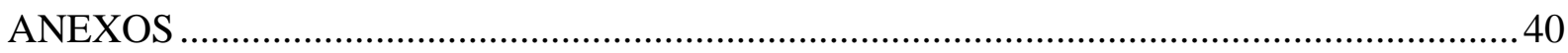




\section{LISTA DE QUADROS}

Quadro 1 - Diferenças entre Bancos e Instituições Financeiras Cooperativas

Quadro 2 - Classificação das operações de crédito em função do atraso no pagamento e o percentual mínimo de provisão regulamentar

Quadro 3 - Revisão da literatura sobre gerenciamento de resultados 


\section{LISTA DE TABELAS}

Tabela 1 - Estatística descritiva das variáveis do modelo (3.3)

Tabela 2 - Matriz de correlação de Pearson entre as variáveis do modelo (3.3)

Tabela 3 - Resultados de estimação do modelo (3.3)

Tabela 4 - Relação de cooperativas de crédito que compõem a amostra do estudo 


\section{LISTA DE ABREVIATURAS E SIGLAS}

BCB - Banco Central do Brasil

BNDES - Banco Nacional do Desenvolvimento

CFC - Conselho Federal de Contabilidade

CMN - Conselho Monetário Nacional

COSIF - Plano Contábil das Instituições do Sistema Financeiro Nacional

CPC - Comitê de Pronunciamentos Contábeis

EACB - European Association of Co-operative Bank

FGCoop - Fundo Garantidor do Cooperativismo de Crédito

GR - Gerenciamento de Resultados

IAS - International Accounting Standard

IASB - International Accounting Standards Board

IF - Instituições Financeiras

MERCOSUL - Mercado Comum do Sul

OCB - Organização das Cooperativas Brasileiras

OIT - Organização Internacional do Trabalho

PCLD - Provisão de Crédito de Liquidação Duvidosa

Pronaf - Programa Nacional de Fortalecimento da Agricultura Familiar

SFN - Sistema Financeiro Nacional

SNCC - Sistema Nacional de Crédito Cooperativo 


\section{INTRODUÇÃO}

O Comitê de Pronunciamentos Contábeis (CPC), por meio de sua Estrutura Conceitual - CPC 00 (R1), de 02 de dezembro de 2011, defende que a informação contábil, em sua essência, tem a função de reportar aos usuários a posição patrimonial fidedigna da entidade de forma a melhorar a confiança e a contribuir com a estabilidade econômica. Apesar disso, as informações financeiras relevantes, capazes de influenciar a tomada de decisão dos usuários, podem sofrer influência por parte dos gestores e assim apresentar discricionariedade na sua forma de mensuração (PAULO, 2007).

Silva e Bezerra (2010) apontam a existência de subjetividade no registro dessas informações, resultante do processo conhecido como Gerenciamento de Resultados (GR), que encontra espaço para ser utilizado quando as normas contábeis permitem, a cargo dos gestores, um espaço para julgar o melhor método para apresentar a posição financeira.

No caso das Instituições Financeiras (IFs) o principal accrual utilizado para essa finalidade, segundo Kanagaretnam, Lobo e Mathieu (2003), é a constituição da Provisão de Crédito de Liquidação Duvidosa (PCLD), devido a discricionariedade admitida aos gestores para eventuais manipulações contábeis, em linha com o que afirma Goulart (2007), em colocar que o GR no Sistema Financeiro Nacional (SFN) ocorre devido a busca dos gestores pela constância de lucros e distanciamento de riscos (income smoothing).

Como parâmetro de constituição de PCLD no âmbito do SFN, a Resolução CMN 2.682, de 21 de dezembro de 1999, prevê que as operações de crédito devem ser classificadas, por ordem crescente de risco, sendo requerido um percentual de provisão para perdas em cada nível de risco, em uma escala crescente que varia de $0 \%$ para o nível AA até $100 \%$ para o nível $\mathrm{H}$. Dessa forma, Niyama (2001), afirma que a Resolução fortalece e atribui uma responsabilidade maior para as instituições financeiras, por exigir que as políticas e procedimentos para concessão de crédito sejam fundamentados em bases técnicas, além de colaborar para uma divulgação mais transparente das informações sobre o nível de qualidade da carteira de crédito com detalhamento dos riscos atribuídos.

Diversos autores discutem o gerenciamento de resultado em bancos, tais como, Martinez (2001), Goulart (2007) e Zendersky (2005), porém os estudos de GR em cooperativas de crédito ainda são poucos incisivos. 
Assim, apresenta-se a seguinte problemática: "a parcela discricionária das despesas de provisão para créditos de liquidação duvidosa é utilizada como instrumento para o gerenciamento de resultados pelas cooperativas de crédito no Brasil?’. O objetivo geral desse trabalho, é, portanto, analisar empiricamente se o componente discricionário das despesas de provisão para créditos de liquidação duvidosa possui relação direta com o lucro líquido ajustado antes da provisão.

Um sistema financeiro sólido e eficiente depende da transparência das informações disponíveis no mercado, o que faz dessa pesquisa um instrumento que visa contribuir com a literatura sobre o gerenciamento de resultados no âmbito do sistema financeiro. Tendo em vista que as cooperativas de crédito apresentam características diferentes dos bancos no que se refere a imagem dos administradores, custo do capital e a remuneração dos dirigentes, o GR também pode apresentar comportamentos distintos. Dessa forma, procura-se contribuir também no âmbito da literatura das instituições financeiras cooperativas.

Para o alcance desse objetivo, serão realizados testes estatísticos por meio de uma pesquisa quantitativa e, em sua essência, caracteriza-se como descritiva e explicativa, tendo como base o relatório IF.data, publicado semestralmente pelo Banco Central do Brasil (BCB).

Para realização dos testes empíricos, foram selecionadas as 500 maiores cooperativas de crédito singulares ranqueadas por ativo total, tendo como base o período de março de 2013 a junho de 2017. Através desses testes, será possível concluir se há ou não gerenciamento de resultados por parte das cooperativas de crédito no Brasil por meio da discricionariedade na constituição da PLCD.

O trabalho foi estruturado em cinco seções, a saber: introdução (Seção 1); a fundamentação teórica, subdividida em sistema cooperativo nacional, PCLD em operações de crédito, gerenciamento de resultados e gerenciamento de resultados em instituições financeiras (Seção 2); os procedimentos metodológicos aplicados para realização dos testes empíricos (Seção 3); a análise dos resultados (Seção 4); e as considerações finais do estudo (Seção 5). 


\section{FUNDAMENTAÇÃO TEÓRICA}

\subsection{Sistema Nacional de Crédito Cooperativo (SNCC)}

De acordo com a Organização Internacional do Trabalho (OIT, 2001), conceitua-se cooperativa como:

Uma associação de pessoas que se uniram voluntariamente para realizar um objetivo comum, através da formação de uma organização administrada e controlada democraticamente, realizando contribuições equitativas para o capital necessário e aceitando assumir de forma igualitária os riscos e benefícios do empreendimento no qual os sócios participam ativamente (Recomendação $n^{\circ} 127$ ).

Com relação às cooperativas do mercado financeiro, Meinen e Port (2014) trazem a ideia de que os lucros para essas entidades são, na verdade, excedentes ou "sobras" apurados pelo resultado de produtos e serviços no fim de cada ciclo anual. Dessa forma, considera-se dupla condição de dono e membro da cooperativa (associados) para distribuição, de forma proporcional ao capital integralizado, do ganho ou perda apurados.

Os autores ainda apontam a diferença entre os associados de uma cooperativa e clientes de um banco convencional. Os membros cooperam-se para satisfazer suas necessidades econômicas recíprocas, enquanto a condição de cliente bancário não gera nenhum tipo de retorno pelos resultados atingidos.

Em suma, em uma cooperativa financeira todos têm o mesmo poder de voto nas decisões e políticas, sendo possível avaliar melhor se o capital está sendo bem administrado. Destaca-se que as cooperativas financeiras não são bancos comerciais/múltiplos, sendo diferentes nos aspectos destacados no Quadro 1.

Quadro 1: Diferenças entre Bancos e Instituições Financeiras Cooperativas

\begin{tabular}{|l|l|}
\hline \multicolumn{1}{|c|}{ Bancos } & \multicolumn{1}{|c|}{ Instituições Financeiras Cooperativas } \\
\hline São sociedades de capital & São sociedades de pessoas \\
\hline $\begin{array}{l}\text { Controle exercido na proporção do número de } \\
\text { ações }\end{array}$ & $\begin{array}{l}\text { Voto com mesmo peso para todos em uma } \\
\text { assembleia }\end{array}$ \\
\hline Deliberações concentradas & Decisões compartilhadas \\
\hline Administradores terceiros (de mercado) & Administradores associados \\
\hline Cliente & Associado \\
\hline Atuação em grandes centros urbanos & Forte atuação em comunidades do interior \\
\hline Sem vínculo com a comunidade & Comprometidas com a comunidade \\
\hline Lucro por excelência & Sobras distribuídas \\
\hline Regulados pela Lei das Sociedades Anônimas & $\begin{array}{l}\text { Reguladas pela Lei Cooperativista } \\
\text { Complementar no 130/2009) }\end{array}$ \\
\hline
\end{tabular}

Fonte: Meinen e Port (2014) com adaptações. 
O Sistema Nacional de Crédito Cooperativo (SNCC) é composto por cooperativas de crédito organizadas em três níveis: singulares, que têm foco em prestação de serviços; centrais, que tratam da organização em maior escala dos serviços das filiadas, facilitando a utilização recíproca dos serviços; confederações, que têm por propósito defender os interesses das cooperativas singulares, além de promover a padronização, supervisão e integração operacional, financeira, normativa e tecnológica. Destaca-se, que no caso das singulares, é opcional pertencer a um sistema de crédito (PINHO; PALHARES, 2010).

Elas são regidas pela Lei $\mathrm{n}^{\circ} 4.595$, de 31 de dezembro de 1964, que dispõe sobre a política de instituições monetárias, bancárias e creditícias; pela Lei n ${ }^{\circ}$ 5.764, de 16 de dezembro de 1971, responsável por definir a Política Nacional de Cooperativismo; e pela Lei Complementar $\mathrm{n}^{\circ} 130$, de abril de 2009, que conferiu ao SNCC a condição de operacionalidade idêntica às dos bancos em geral, sem prejudicar em suas particularidades societárias. Além disso, quanto à supervisão e regulação, essas ficam a cargo do Conselho Monetário Nacional $(\mathrm{CMN})$, por meio do Banco Central do Brasil (BCB), incluindo a autorização para funcionamento, a aprovação de eleição de administradores, conselheiros fiscais e o monitoramento do segmento.

Com relação à segurança e solidez, Meinen e Port (2014) afirmam que as cooperativas têm de cumprir regras operacionais e diretrizes de governança semelhantes às dos bancos brasileiros, e para situações de risco de solvência contam como um fundo inter sistêmico nacional, o Fundo Garantidor do Cooperativismo de Crédito (FGCoop), que tem como objetivo garantir o pagamento dos depósitos dos associados até o limite regulamentar definido.

Dessa forma, os controles das cooperativas devem assegurar patrimônio suficiente para fazer face aos riscos de suas operações, cumprir as diretrizes de Basileia; contar com gestores idôneos e qualificados com nomes submetidos ao BCB, e acumular reservas, em regime de solidariedade com as cooperativas do mesmo sistema para que restabeleça o equilíbrio econômico-financeiro de entidades com dificuldades de continuidade operacional.

Segundo a European Association of Co-operative Bank (EACB, 2016), as instituições financeiras cooperativas são parte essencial no processo de desenvolvimento econômico de um país e fundamentais para democratização do crédito, e para isso, contam com suporte de seus bancos cooperativos com o propósito de integrar a liquidez sistêmica e promover soluções de 
produtos e serviços, além de fazer parte do sistema nacional de pagamento.

Em linha com o sistema financeiro, as confederações de cooperativas de crédito têm constituído empresas e entidades de natureza não-cooperativas, para cuidar de negócios específicos e de atividade especializadas. São elas: corretoras de seguro, seguradoras, administradoras de cartões, consórcios, distribuidoras de títulos e valores mobiliários, fundações de previdência e outras entidades sem fins lucrativos.

De acordo com Meinen e Port (2014) são várias as operações financeiras que os associados realizam em sua cooperativa, mas que são operacionalizadas por bancos cooperativos ou por convênio com bancos comerciais, como por exemplo: aplicação em fundos de investimento, poupança rural, tomada de recursos oriundos do Banco Nacional do Desenvolvimento (BNDES), Programa Nacional de Fortalecimento da Agricultura Familiar (Pronaf) e outros produtos e serviços bancários. A Organização das Cooperativas Brasileiras (OCB , 2010) afirma que o maior negócio das cooperativas de crédito está relacionado ao repasse de crédito rural. Com isso, grande parte dos pontos de atendimentos está localizado em cidades com menos de 50 mil habitantes, sendo que em 2015, cerca de $43 \%$ dos associados não tinham vínculos financeiros com outras instituições.

\subsection{Provisão para Créditos de Liquidação Duvidosa (PCLD)}

Iudícibus et al. (2010, p. 63), apresentam o conceito de Provisão para Crédito de Liquidação Duvidosa (PCLD) como "estimativa do valor recuperável do ativo, onde é valorizada a informação ao usuário da contabilidade sobre o real valor que se espera no ativo". Com isso, Iudícibus e Marion (2009) afirmam que a parte não embolsada em decorrência do inadimplemento dos devedores deve ser subtraída do Contas a Receber, com o título de Provisão para Crédito de Liquidação Duvidosa. Em suma, as reais expectativas de recebimentos a prazo devem ser demostradas pela contabilidade.

As instituições financeiras trabalham com um plano de contas padronizado sob a responsabilidade do $\mathrm{CMN}$ por meio do $\mathrm{BCB}$, conhecido como Plano Contábil das Instituições do Sistema Financeiro Nacional (COSIF). Essa diretriz contábil ainda nomeia a provisão de crédito duvidosa como PCLD e estabelece critério específicos ao registro de perdas futuras referentes as operações presentes, já que o recebimento de um direito não é líquido, uma vez que a empresa está sujeita ao risco de crédito. 
Logo, a IAS 39 orienta para a realização dos testes de impairment de empréstimos e recebíveis seja promovido com a análise dos créditos relevantes, por meio da verificação dos agrupamentos das operações de acordo com as características de risco de crédito e dos indicativos da capacidade do devedor de pagar as quantias devidas conforme os termos contratuais.

Para Almeida (2014, p 57), a entidade deve aplicar certos procedimentos para assegurar que seus ativos estejam registrados contabilmente por valor que não exceda seus valores de recuperação. Assim, o pronunciamento conceitua a perda por impairment como o resultado do custo amortizado e do valor presente do fluxo de caixa futuro que foi estimado.

De acordo com Ferreira (2010), a provisão deve refletir de forma fidedigna o valor da possível perda das operações de crédito, para isso as instituições financeiras adotam procedimentos específicos em comparação a outros tipos de entidade no provisionamento de clientes duvidosos, porque a atividade fim é o próprio capital. Para Nyama e Gomes (2005) a constituição da PCLD traz melhoria na qualidade de mensuração do risco em operações de crédito baseadas em uma visão mais consistente, levando em conta a inadimplência, contexto econômico e a capacidade de pagamento do devedor.

O CMN, por meio da Resolução no 2.682/99, estabeleceu critérios para constituição de provisão de crédito de liquidação duvidosa nas operações realizadas no âmbito do Sistema Financeiro Nacional (SFN). De acordo com essa norma, é de responsabilidade das instituições financeiras a classificação da operação no nível de risco correspondente, com base em metodologia consistente, que considere a análise dos seguintes aspectos: situação econômicofinanceira do tomador; endividamento; capacidade de geração de resultados; pontualidade nos pagamentos; e garantias.

Dessa forma, as IFs seguem metodologia prevista na Resolução CMN nº 2.682/99, com relação aos atrasos para classificação de risco, conforme Quadro 2. A constituição de PCLD deve respeitar os limites percentuais não inferior ao somatório de percentuais dos níveis demonstrados no Quadro 2. Com isso, Annibal (2009) concorda que o indicador mais adequado para medir a inadimplência stricto sensu do setor bancário é com base no número de operações em atraso. 
Quadro 2: Classificação das operações de crédito em função do atraso no pagamento e o percentual mínimo de provisão regulamentar

\begin{tabular}{|c|c|c|}
\hline Nível de Risco & Atraso em dias & $\begin{array}{c}\text { \% Mínimo de Provisão } \\
\text { Regulamentar }\end{array}$ \\
\hline AA & - & $0,0 \%$ \\
\hline A & - & $0,5 \%$ \\
\hline B & 15 a 30 & $1,0 \%$ \\
\hline C & 31 a 60 & $3,0 \%$ \\
\hline D & 61 a 90 & $10 \%$ \\
\hline E & 91 a 120 & $30 \%$ \\
\hline F & 121 a 150 & $50 \%$ \\
\hline G & 151 a 180 & $70 \%$ \\
\hline H & Superior a 180 & $100 \%$ \\
\hline
\end{tabular}

Fonte: elaborado pelo autor baseado na Resolução BCB No 2.682/99.

Em caso de renegociação a norma prevê que devem ser mantidas, no mínimo, no mesmo nível de risco em que estiverem classificadas, mesmo estando a operação no nível " $H$ " já registrada como prejuízo.

Para Niyama (2001), a Resolução CMN n ${ }^{\circ}$ 2.682/99 trouxe uma metodologia de constituição de provisão para créditos de liquidação duvidosa que fortalece e atribui mais uma função da área de crédito das IFs, justamente por exigir que as políticas e procedimentos para concessão de crédito sejam fundamentados em bases técnicas. A principal contribuição, segundo o autor, é a divulgação mais transparente das informações sobre o nível de qualidade da carteira de crédito com detalhamento dos riscos atribuídos. Outro ponto importante do normativo é a busca pela harmonização com os procedimentos adotados também em outros países, principalmente no âmbito do MERCOSUL.

Diversos autores discutem o uso da conta patrimonial de PCLD e sua utilização no gerenciamento de resultados, dado ao elevado grau de discricionariedade utilizado pela gestão e consequentemente facilitando a manipulação dos dados contábeis. Para Greenawalt e Sinkey (1988), o julgamento dos gestores de bancos determinam a base de mensuração da PCLD, o que gera um lançamento contra uma conta de despesas operacionais, no qual a natureza discricionária do processo de projeção de perdas e seu uso ao longo de períodos sucessivos fornece aos gestores a oportunidade de suavizar resultados.

Bischoff e Lustosa (2014) apontaram que os bancos brasileiros utilizam da PCLD para gerenciar resultados, ou seja, realizam provisões superiores ao mínimo regulamentar em períodos de lucro bancário alto, como forma de criar uma "reserva" para períodos posteriores em que o lucro venha a ser menor. Isso vai de encontro com o que afirma Kanagaretnam et al. 
(2003, p. 74), “o desempenho atual e futuro de um banco influencia seu nível de PCLD”.

Dantas et al. (2013) demonstraram que a incorporação das variáveis macroeconômicas e atributos da carteira de crédito melhoram a investigação empírica das discricionariedades praticadas pelos bancos. Portanto, os modelos utilizados para estimar a PCLD pelos bancos, incorporando variáveis que representam a situação macroeconômica e os atributos da carteira de crédito, melhoram a identificação da discricionariedade praticada pela administração.

Dessa forma, verifica-se que a PCLD é uma conta patrimonial representativa, por ser considerada uma fonte de proteção contra o risco de crédito, que por sua vez é fator inerente às atividades de financiamento. Portanto, verifica-se que a prática do GR em instituições bancárias com o uso da PCLD acontece devido utilização da parcela discricionária dada a possibilidade de julgamentos subjetivos por parte da administração tendo em vista os incentivos.

\subsection{Gerenciamento de Resultados (GR)}

A estrutura conceitual da contabilidade prevista no CPC 00 R1 (2011) afirma que a informação contábil é elaborada e apresentada para usuários externos e internos em geral com finalidades distintas e necessidades diversas, portanto, deve fornecer informações que sejam úteis na tomada de decisões econômicas e avaliações por parte dos usuários.

Dessa forma, a qualidade da informação contábil é comprometida pelo gerenciamento de resultados por parte dos gestores motivados por razões diversas, assim como provoca distribuições de riquezas inconsistentes com danosas consequências para os investidores e usuários em geral.

Murcia e Carvalho (2007) ressaltam que mesmo utilizando corretamente os princípios e normas contábeis, sempre existirá o exercício do julgamento dos preparadores das demonstrações contábeis e a realização de estimativas e previsões por parte dos gestores.

Segundo Goulart (2007, p. 6) o conceito de gerenciamento de resultado pode ser assim definido:

Conjunto de ações intencionais, por parte dos preparadores de demonstrações financeiras, com impactos sobre a representação contábil da entidade, dentro dos limites permitidos pelas normas e padrões contábeis, tendo em vista o atendimento de interesses dos gestores da organização objeto da divulgação financeira.

Seguindo esse raciocínio, Martinez (2001) afirma que o resultado do período é constituído de uma parte advinda das atividades normais da empresa, que são as acumulações 
não discricionárias (accruals não discricionários), e outra decorrente de métodos que a administração da entidade julga serem os mais apropriados para apresentar adequadamente a posição financeira, denominadas acumulações discricionárias (accruals discricionários).

Nesse contexto, distinguir o gerenciamento de resultados de fraude torna-se essencial. Autores como Martinez (2001) afirmam que o ato de gerenciar as informações financeiras com foco em alcançar resultados desejados, distorce o desempenho das empresas. Apesar disso, não pode ser confundido com operação fraudulenta, por atuar dentro do que é permitido pelas normas contábeis. Na mesma linha de entendimento, o Conselho Federal de Contabilidade (CFC) apresentou por meio da Resolução n. ${ }^{\circ} 1.203$ de 27 de novembro de 2009, que a fraude é qualificada pelo "ato intencional de omissão ou manipulação de transações, adulteração de documentos, registros e demonstrações contábeis".

A literatura sobre o assunto apresenta que a principal razão para o gerenciamento de resultado são os incentivos aos gestores. Dessa forma, Zendersky (2007) cita o fato de que as normas contábeis não alcançam todas as situações e, além disso, em alguns casos essas regras permitem a possibilidade de escolha sobre como aplicar.

Outra razão apresentada por Mohanram (2003) é a tendência da alta administração em demonstrar o crescimento almejado, bons índices de rentabilidade e lucratividade, além de priorizar os incentivos próprios na participação dos resultados ou determinada cláusula contratual.

\subsubsection{Gerenciamento de Resultados em Instituições Financeiras (IFs)}

Essas motivações, sob a ótica das instituições financeiras, sofrem algumas especificidades determinadas pelo negócio da entidade. A particularidade dos bancos é apresentar interesse na suavização de resultados (income smoothing), no qual Goulart (2007) afirma ser a meta pela constância de lucros e distanciamento de riscos, ou seja, menor volatilidade de apresentação dos resultados.

Essa ideia vai ao encontro com Collins et al (1995) em apontar que resultados constantes geram menos atenção por parte dos reguladores, como também promovem mais facilidade para captação de recursos no mercado. Outras motivações das instituições financeiras são os planos de remuneração variável de executivos com bônus vinculados a números contábeis e à redução do custo de capital. 
Segundo Goulart (2007), para um sistema econômico sólido, é essencial ter transparência nas informações contábeis, pois as instituições financeiras dependem de boa situação de liquidez e capacidade de geração de resultados baseado na confiabilidade dos clientes e usuários. Para isso, é necessário controles internos eficazes e adequada gestão de riscos.

Neste contexto, percebe-se a importância das pesquisas acadêmicas no âmbito do Sistema Financeiro Nacional (SFN) e do SNCC no que diz respeito ao gerenciamento de resultados e seus desdobramentos tendo em vista as atividades desenvolvidas pelas instituições financeiras e pelas cooperativas de crédito, pois são de grande relevância para o desenvolvimento socioeconômico do país.

Devido a problemas financeiros nas empresas norte-americanas na metade da década de 1980, começaram a surgir estudos acadêmicos sobre a temática do gerenciamento de resultados. Logo após isso, no Brasil, também diversos pesquisadores investigaram o assunto. Dessa forma, demonstra-se no Quadro 3 um panorama dos autores e suas contribuições apresentadas com relação à ideia do gerenciamento de resultados.

Quadro 3: Revisão da literatura sobre gerenciamento de resultados

\begin{tabular}{|c|c|}
\hline Autor/Ano & Contribuição \\
\hline \multicolumn{2}{|r|}{ Literatura Estrangeira } \\
\hline Dye (1988) & Vantagem do gestor devido a ideia de assimetria de informações. \\
\hline Schipper (1989) & $\begin{array}{l}\text { Intervenção proposital no processo de elaboração das demonstrações } \\
\text { financeiras, com o objetivo de obter algum benefício particular. }\end{array}$ \\
\hline Healy e Wahlen (1999) & $\begin{array}{l}\text { Modificação dos resultados apresentados aos stakeholders para influenciar } \\
\text { em contratos baseados em números contábeis. }\end{array}$ \\
\hline $\begin{array}{l}\text { Brewer, Angel e Mautz } \\
(2002)\end{array}$ & $\begin{array}{l}\text { Revisão da literatura feita após a falência da Enron nos sites do Wall Street } \\
\text { Journal e ABI INFORM utilizando como busca o termo "earnings } \\
\text { management" registrando consideravelmente o crescimento de pesquisas } \\
\text { sobre o assunto. }\end{array}$ \\
\hline $\begin{array}{l}\text { Kanagaretnam, Lobo e } \\
\text { Mathieu (2003) }\end{array}$ & $\begin{array}{l}\text { As provisões representam, de modo geral, os maiores accruals dos bancos, } \\
\text { desempenhando papel fundamental nas decisões dos gestores sobre } \\
\text { eventuais manipulações contábeis. }\end{array}$ \\
\hline Mohanram (2003) & $\begin{array}{l}\text { Classificação incorreta e intencional dos resultados levando a números } \\
\text { finais que teriam sido diferentes na ausência de alguma manipulação. }\end{array}$ \\
\hline \multicolumn{2}{|r|}{ Literatura Nacional } \\
\hline Martinez (2001) & $\begin{array}{l}\text { As operações de mercado aberto criam motivações para os } \\
\text { administradores gerenciarem os resultados. }\end{array}$ \\
\hline Zendersky (2005) & $\begin{array}{l}\text { A maior parte do montante das provisões para créditos de liquidação } \\
\text { duvidosa é explicada pela parcela discricionária, e não por exigência } \\
\text { regulamentar, resultado que representa um indício de comportamento de } \\
\text { gerenciamento de resultados por meio das despesas de provisão para } \\
\text { créditos de liquidação duvidosa em instituições financeiras. }\end{array}$ \\
\hline Goulart (2007) & $\begin{array}{l}\text { Emprego das operações de crédito e derivativos na suavização de } \\
\text { resultados contábeis e também dos ajustes positivos a valor de mercado }\end{array}$ \\
\hline
\end{tabular}




\begin{tabular}{|l|l|}
\hline & de TVM em instituições financeiras. \\
\hline Macedo e Kelly (2016) & $\begin{array}{l}\text { Existem indícios de maiores práticas de gerenciamento de resultados com } \\
\text { o uso da PCLD em bancos com capital estrangeiro. }\end{array}$ \\
\hline
\end{tabular}

Fonte: elaborado pelo autor baseado nos dados da pesquisa.

\subsubsection{Gerenciamento de Resultados em Cooperativas de Crédito}

A literatura internacional sobre cooperativas de crédito com relação ao gerenciamento de resultados ainda não é robusta e poucos autores discorreram a respeito. Hillier et al. (2008) e Brown e Davis (2008) divergiram seus resultados sobre a utilização ou não dessa prática no resultado das instituições financeiras cooperativas na Austrália. Isso demonstra que não há consenso entre os acadêmicos sobre a utilização ou não por parte das cooperativas de crédito no que diz respeito ao gerenciamento de resultados.

Hillier et al. (2008) afirmam que, em função de normas de exigência de capital, assim como os bancos, as cooperativas de crédito se veem obrigadas a adequar seu índice risco, com as cooperativas de crédito sendo motivadas a se utilizar das práticas de gerenciamento de resultados para adequação da proporção de seu patrimônio líquido em relação aos ativos ponderados pelo risco.

Por outro lado, Brown e Davis (2008) expõem que, a fidelidade de seus associados e o poder de ofertar as condições melhores que o mercado com relação às taxas de depósitos e operações de crédito, fazem com que essas instituições tenham incentivos para melhorar o resultado de suas carteiras frente a uma necessidade de melhor desempenho, não partindo para práticas de gerenciamento de resultados.

Com relação aos estudos acadêmicos sobre gerenciamento de resultados com foco em cooperativas de crédito no Brasil, Maia et al. (2013) apontaram que essas instituições não gerenciam seus resultados com o propósito de adequação ao capital regulatório. Por outro lado, os resultados apontam ocorrência de suavização de resultados e gerenciamento de resultados com o propósito de evitar reportar perdas. 


\section{PROCEDIMENTOS METODOLÓGICOS}

Dado o exposto, o presente estudo consiste em avaliar se as cooperativas de crédito no Brasil utilizam a PCLD como mecanismo para o gerenciamento de resultados, ou seja, se o componente discricionário das despesas de provisão para créditos de liquidação duvidosa possui relação direta com o lucro líquido ajustado antes da provisão nas instituições financeiras cooperativas em funcionamento no Brasil.

Uma pesquisa descritiva é caracterizada segundo Prodanov e Freitas (2013), como aquela em que o pesquisador não interfere nos dados, apenas registra e descreve os mesmos. E, quando uma pesquisa vai além dessa simples verificação de existência de relação entre variáveis, e determina a natureza dessa relação, têm-se a aproximação da pesquisa descritiva com a explicativa. Dessa forma, esse estudo em sua essência caracteriza-se na classificação descritiva e explicativa.

Assim, de acordo com Gil (2002), a pesquisa explicativa pode ser a continuação de outra descritiva, uma vez que a identificação dos fatores que determinam um fenômeno exige que este esteja suficientemente descrito e detalhado. Em linha com esse raciocínio, tem-se que a pesquisa documental se baseia em materiais que ainda não receberam um tratamento analítico, ou que ainda podem ser reelaborados de acordo com os objetos da pesquisa.

Com relação à abordagem do problema e análise dos dados, o presente estudo é classificado como quantitativo, por empregar uma análise mais profunda em relação ao fenômeno (RAUPP; BEUREN, 2006).

Quanto ao procedimento adotado para coleta dos dados, o presente estudo é caracterizado como uma pesquisa documental, pelo fato de utilizar-se das demonstrações financeiras elaboradas pelas cooperativas de crédito e divulgadas trimestralmente pelo $\mathrm{BCB}$, por meio do Relatório IF.data.

\subsection{Hipótese de Pesquisa}

Assim como ocorre nos bancos, as despesas de provisão para créditos de liquidação duvidosa também são representativas nas demonstrações contábeis das cooperativas que atuam no Brasil. Essas despesas são divulgadas trimestralmente pelo BCB por meio do Relatório IF.data. 
Fundamentada nos estudos anteriores e nas seções 2.1 e 2.3, a presente pesquisa aborda o gerenciamento de resultados por meio das acumulações discricionárias. Segundo Dechow (1994), no estudo sobre resultados contábeis, os accruals são melhores preditivos que o fluxo de caixa. Sendo assim, é verificada a utilização das despesas de provisão para créditos de liquidação duvidosa com a finalidade de gerenciamento de resultados pelas instituições que atuam no SNCC, definindo a seguinte hipótese a ser testado empiricamente:

$\mathbf{H}_{1}$ : As instituições financeiras cooperativas brasileiras utilizam as provisões de crédito de liquidação duvidosa como mecanismo para gerenciamento de resultados.

\subsection{Definição do Modelo}

O modelo proposto para a identificação da parcela discricionária da PCLD se baseia nos estudos anteriores, analisados na Seção 2, acrescendo-se variáveis explicativas que traduzam as recomendações normativas (PCLD Regulamentar) e preceitos econômicos (PIB Real) na constituição dessas provisões para perdas com créditos bancários. Para o propósito de responder à hipótese de pesquisa formulada foram utilizados modelos de dados em painel desbalanceado com efeitos fixos.

Inicialmente, é importante apurar a parcela discricionária da PCLD considerando o seguinte método:

$$
\begin{aligned}
& \text { PCLD }_{i t}=\text { PCLDnd }_{i t}+\text { PCLDd }_{i t} \\
& \text { PCLDd }_{i t}=\text { PCLD }_{i t}-\text { PCLDnd }_{i t}
\end{aligned}
$$

Onde:

PCLD it: estoque de PCLD contabilizado, da cooperativa $i$, no momento $t$, conforme Relatório IF.data.

PCLDndi: valor de PCLD não discricionária, da cooperativa $i$, no momento $t$, calculado em função do percentual regulamentar dos ratings aplicados em cada conta de nível de risco do balancete da cooperativa, conforme Quadro 2.

PCLDd: Parcela de PCLD discricionária, da cooperativa $i$, no momento $t$.

Identificada a parcela discricionária da PCLD, é utilizado o seguinte modelo para concluir sobre a hipótese de pesquisa:

$\triangle \mathrm{PCLDd}_{\mathrm{it}}=\beta_{\mathrm{o}}+\beta_{1} \mathrm{LLAJ}_{\mathrm{it}}+\beta_{2} \triangle \mathrm{OPC}_{\mathrm{it}}+\beta_{3} \mathrm{PIB}_{\mathrm{it}}+\beta_{4}(\triangle \mathrm{LLAJ} \text { neg })_{\mathrm{it}}+\beta_{5}(\mathrm{LLAJ} \text { neg })_{\mathrm{it}}+\epsilon_{\mathrm{it}}$

Onde:

$\triangle$ PCLDd $_{\mathrm{it}}$ : Variação da PLCD discricionária (modelo 3.2) da cooperativa $i$, considerando a diferença do momento $t$ e o período anterior, dividido pelo ativo total do período $t-1$.

$\mathrm{LLAJ}_{\text {it: }}$ lucro líquido ajustado antes da PCLD discricionária $\left(\triangle \mathrm{PCLDd}_{\mathrm{i}} \mathrm{t}\right)$ da cooperativa $i$, no momento $t$, dividido pelo ativo total do período $t$ - 1 .

$\triangle \mathrm{OPC}_{\mathrm{it}}$ : variação do estoque de operações de créditos da cooperativa $i$, considerando a diferença do momento $t \mathrm{e}$ o período anterior, dividido pelo ativo total do período $t-1$. 
PIBt: variação do Produtor Interno Bruto trimestral do país, no período $t$.

LLAJneg it: variável dummy, assumindo valor 1 quando o lucro líquido antes da PCLD discricionária da cooperativa $i$, no período $t$, é negativo, e 0 para as demais.

$\triangle$ LLAJneg it: variável dummy, assumindo valor 1 quando o lucro líquido antes da PCLD discricionária da cooperativa i, no período t, variou negativamente em relação ao período anterior, e 0 para as demais.

Para testar $\mathrm{H}_{1}$, tem-se como variável de interesse o lucro líquido ajustado ( $\left.\boldsymbol{L} \boldsymbol{L} \boldsymbol{A} \boldsymbol{J}_{i t}\right)$. Dessa forma, confirma-se o gerenciamento de resultados em cooperativas de crédito no Brasil se houver constatação de relação positiva e estatisticamente relevante entre esse resultado com a variação da PCLD discricionária ( $\triangle \boldsymbol{P C} \boldsymbol{L} \boldsymbol{D} \boldsymbol{d}_{i t}$ ), considerada no modelo uma variável dependente por demostrar a existência de manipulação nos resultados influenciado pela discricionariedade dos gestores tendo como base o comportamento das demais variáveis. Por outro lado, caso seja apurada uma relação negativa ou irrelevante, a hipótese $\mathrm{H}_{1}$ será rejeitada no modelo testado.

Utilizou-se como variáveis de controle a variação do estoque das operações de crédito das cooperativas $\left(\triangle \boldsymbol{O P C}_{i t}\right)$, o Produto Interno Bruto do país $(\boldsymbol{P I B})$, a variável dummy representativa do prejuízo da cooperativa no período (LLAJneg $\boldsymbol{g}_{i t}$ ) e a variável dummy que representa a variação negativa em relação ao período anterior da cooperativa. Com isso, analisou-se a relação da PCLD discricionária com essas variáveis como forma de constar que os resultados do modelo são consistentes e confirmam o teste da hipótese. A estimação com o uso de dados em painel com efeitos fixos nos períodos se justifica pela possibilidade de controlar a heterogeneidade temporal existente nas séries (BALTAGI, 2008).

Dessa forma, as observações são avaliadas em duas dimensões, sendo uma delas a unidade amostral e a outra o tempo $(\boldsymbol{t})$. Espera-se, portanto, que a $\triangle \boldsymbol{P C} \boldsymbol{L D d}$ das cooperativas de crédito, no momento $\boldsymbol{t}$, esteja influenciada pelo comportamento das variáveis independentes.

\subsection{População e Amostra}

Conforme mencionado nesse estudo, o SNCC é composto por cooperativas de crédito centrais e singulares, sendo que toda operação negocial com os associados está a cargo das singulares, o que configura as centrais a função de suporte operacional na prestação de serviços e o acesso aos produtos do mercado financeiro. Dessa forma, pelas finalidades e propósitos distintos, optou-se por analisar apenas as singulares, pois o exame em conjunto com os dados das centrais poderia causar viés nos resultados apontados.

De acordo com dados do BCB, em dezembro de 2016 existiam 35 centrais e 1.017 
singulares em atividade no país. A presente pesquisa trabalha com dados em painel não balanceados, no qual são analisadas as 500 maiores instituições financeiras cooperativas classificas por ativos totais considerando a data-base de junho de 2017. O quantitativo de cooperativas analisadas deve-se ao fato de que as instituições com menor porte de operações podem distorcer a amostra pelo nível dos controles internos mantidos, ou muitas vezes, não apresentarem a divulgação das informações.

A parte empírica da pesquisa foi implementada a partir dos dados contábeis do consolidado operacional dessas cooperativas, classificadas no relatório como Instituições Bancárias Independentes III (BIII) e pelo macrossegmento Cooperativas de Crédito Singulares (b3S). Cabe ressaltar que, delimitou-se como período analisado as datas-bases entre março de 2013 a junho de 2017, visto que essa informação foi incluída em 2013 no referido relatório.

$\mathrm{Na}$ primeira etapa, para compor a amostra foram coletados dados de todas as cooperativas singulares dos sistemas de cooperativas de crédito mencionados que estiveram em atividade durante o período definido para a análise. Aplicou-se dois critérios de restrição à amostra: o primeiro relacionado à atuação da cooperativa de crédito durante período e o segundo à disponibilidade de dados durante o período. 


\section{DESCRIÇÃO E ANÁLISE DE DADOS}

\subsection{Estatísticas Descritivas}

Considerando que o presente estudo teve como objetivo principal identificar se as instituições financeiras cooperativas brasileiras utilizam as provisões de crédito de liquidação duvidosa como mecanismo para gerenciamento de resultados, foram apuradas as variáveis necessárias para a estimação do modelo (3.3), tendo por base a amostra definida na Seção 3 .

Tabela 1: Estatística descritiva das variáveis do modelo (3.3)

\begin{tabular}{|c|c|c|c|c|c|c|}
\hline Descrição variáveis & $\triangle P C L D d_{i t}$ & $L L A J_{i t}$ & $\triangle O P C_{i t}$ & $P^{\prime} B_{t}$ & LLAJneg & $\triangle L L A J n e g$ \\
\hline Média & 0,0001 & 0,0144 & 0,0258 & $-0,0103$ & 0,4399 & 0,4356 \\
\hline Mediana & 0,0000 & 0,0125 & 0,0203 & $-0,0064$ & 0,0000 & 0,0000 \\
\hline Máximo & 0,0851 & 0,0991 & 1,2009 & 0,0401 & 1,0000 & 1,0000 \\
\hline Mínimo & $-0,0521$ & $-0,1161$ & $-0,5718$ & $-0,5760$ & 0,0000 & 0,0000 \\
\hline Desvio padrão & 0,0023 & 0,0142 & 0,0586 & 0,0288 & 0,4964 & 0,4958 \\
\hline
\end{tabular}

Onde: $\triangle$ PCLDdit: Variação da PLCD discricionária (modelo 3.2) da cooperativa $i$, considerando a diferença do momento $t$ e o período anterior, dividido pelo ativo total do período $t$ - 1 . LLAJ it: lucro líquido ajustado antes da PCLD discricionária ( $\triangle \mathrm{PCLDd}_{\mathrm{i}} \mathrm{t}$ ) da cooperativa $i$, no momento $t$, dividido pelo ativo total do período $t$ - 1 . $\triangle \mathbf{O P C}_{\text {it: }}$ variação do estoque de operações de créditos da cooperativa $i$, considerando a diferença do momento $t$ e o período anterior, dividido pelo ativo total do período $t$ - 1 . PIBt: variação do Produtor Interno Bruto trimestral do país, no período $t$. LLAJ negit: variável dummy, assumindo valor 1 quando o lucro líquido antes da PCLD discricionária da cooperativa $i$, no período $t$, é negativo, e 0 para as demais. $\triangle \mathbf{L L A J}$ neg it: variável dummy, assumindo valor 1 quando o lucro líquido antes da PCLD discricionária da cooperativa $i$, no período $t$, variou negativamente em relação ao período anterior, e 0 para as demais.

Ao avaliar as estatísticas descritivas do modelo conforme a Tabela 1, verifica-se que a média percentual da variação da parcela discricionária da PCLD ( $\left.\triangle \boldsymbol{P C} \boldsymbol{L} \boldsymbol{D} \boldsymbol{d}_{i t}\right)$ em relação ao ativo total é de $0,007 \%$ e a do lucro líquido ajustado $\left(\boldsymbol{L} \boldsymbol{L} \boldsymbol{A} \boldsymbol{J}_{i t}\right)$ é de $0,1 \%$. Na variável de controle da carteira de crédito $\left(\triangle \boldsymbol{O P C _ { i t } )}\right.$ das cooperativas apresentou um crescimento real médio percentual de 2,6\%, enquanto o aumento real médio do PIB per capita $(\boldsymbol{P I B})$ foi de $0,1 \%$.

\subsection{Matriz de Correlação}

Para a identificação das primeiras evidências de gerenciamento de resultados com a utilização da PCLD discricionária, bem como para identificar os riscos de multicolinearidade, a Tabela 2 representa a matriz de correlação de Pearson entre as variáveis do modelo (3.3). 
Tabela 2: Matriz de correlação de Pearson entre as variáveis do modelo (3.3)

\begin{tabular}{|c|c|c|c|c|c|c|}
\hline & $\triangle$ PCLDd $_{i t}$ & $\mathbf{L L A J}_{\text {it }}$ & $\triangle \mathrm{OPC}_{\mathrm{it}}$ & PIBt & $\triangle$ LLAJnegit & LLAJneg \\
\hline$\triangle$ PCLDd $_{\mathrm{it}}$ & 1,0000 & & & & & \\
\hline $\mathbf{L L A J}_{\text {it }}$ & 0,1505 & 1,0000 & & & & \\
\hline$\triangle \mathrm{COPC}_{\mathrm{it}}$ & 0,0412 & 0,0295 & 1,0000 & & & \\
\hline PIBt & 0,0522 & 0,0313 & 0,0964 & 1,0000 & & \\
\hline$\triangle$ LLAJ negit & 0,0200 & $-0,3877$ & $-0,0051$ & $-0,0498$ & 1,0000 & \\
\hline LLAJ neg & $-0,0712$ & $-0,3996$ & $-0,0162$ & $-0,0498$ & 0,1971 & 1,0000 \\
\hline
\end{tabular}

Onde: $\triangle$ PCLDd $_{\mathrm{it}}$ : Variação da PLCD discricionária (modelo 3.2) da cooperativa $i$, considerando a diferença do momento $t$ e o período anterior, dividido pelo ativo total do período $t-1$. LLAJ it: lucro líquido ajustado antes da PCLD discricionária $\left(\triangle \mathrm{PCLDd}_{\mathrm{i}} \mathrm{t}\right)$ da cooperativa $i$, no momento $t$, dividido pelo ativo total do período $t$ - 1 . $\triangle \mathbf{O P C}_{\text {it: }}$ variação do estoque de operações de créditos da cooperativa $i$, considerando a diferença do momento $t$ e o período anterior, dividido pelo ativo total do período $t$ - 1 . PIBt: variação do Produtor Interno Bruto trimestral do país, no período $t$. LLAJ negit: variável dummy, assumindo valor 1 quando o lucro líquido antes da PCLD discricionária da cooperativa $i$, no período $t$, é negativo, e 0 para as demais. $\triangle$ LLAJ neg it: variável dummy, assumindo valor 1 quando o lucro líquido antes da PCLD discricionária da cooperativa $i$, no período $t$, variou negativamente em relação ao período anterior, e 0 para as demais.

A matriz de correlação revela, inicialmente, a relação positiva entre a utilização da PCLD discricionária $\left(\triangle \boldsymbol{P C} \boldsymbol{L} \boldsymbol{D} d_{i t}\right)$ e o lucro líquido ajustado $\left(\boldsymbol{L L A J}{ }_{i t}\right)$, o que representa uma primeira evidência pela corroboração da hipótese $\mathrm{H}_{1}$. Para as variáveis de controle também foram encontradas relações positivas entre o comportamento da PCLD discricionária com

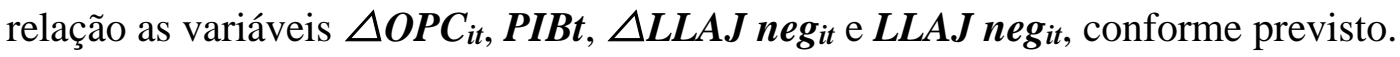

No tocante à relação entre as variáveis independentes, no sentido de identificar riscos de multicolinearidade, não foi identificado nenhum caso em que a correlação tenha ultrapassado o limite de 0,8, que representaria, de acordo com Gujarati (2006), um alto risco de multicolinearidade.

\subsection{Estimação do Modelo e Teste das Hipóteses}

Tendo em vista o objetivo desse estudo, que procura identificar se as cooperativas de crédito no Brasil utilizam a PCLD discricionária como ferramenta para o gerenciamento de resultados, foi estimado o modelo (3.3), com uma variável de interesse ( $\left.\boldsymbol{L} \boldsymbol{L} \boldsymbol{A} \boldsymbol{J}_{i t}\right)$ e quatro de controle ( $\triangle \boldsymbol{O P C}_{i t}, \boldsymbol{P I B}$, LLAJneg e $\Delta \boldsymbol{L L A J n e g}$ ). A partir de evidências de riscos de autocorrelação e heterocedasticidade nos resíduos, o modelo foi estimado com dados em painel, com efeitos fixos nos períodos e uso do método SUR PCSE, que gera parâmetros robustos, mesmo na presença de autocorrelação e heterocedasticidade. A Tabela 3 sintetiza os resultados dessas estimações. 
Tabela 3: Resultados de estimação do modelo (3.3)

\begin{tabular}{|c|c|c|c|}
\hline \multicolumn{4}{|c|}{$\begin{array}{c}\text { Modelo testado: } \\
\triangle \mathrm{PCLDd}_{\mathrm{it}}=\beta_{\mathrm{o}}+\beta_{1} \mathrm{LLAJ}_{\mathrm{it}}+\beta_{2} \triangle \mathrm{OPC}_{\mathrm{it}}+\beta_{3} \mathrm{PIB}_{\mathrm{t}}+\beta_{4}(\triangle \mathrm{LLAJ} \text { neg })_{\mathrm{it}}+\beta_{5}(\mathrm{LLAJ} \text { neg })_{\mathrm{it}}+\epsilon_{\mathrm{it}}\end{array}$} \\
\hline & & $\begin{array}{l}\text { Efeitos fixos } \\
\text { seccionais }\end{array}$ & $\begin{array}{l}\text { Duplo efeitos } \\
\text { fixos }\end{array}$ \\
\hline \multirow{3}{*}{$C$} & $-0,0006$ & $-0,0016$ & $-0,0015$ \\
\hline & $(0,0000)$ & $(0,0000)$ & $(0,0000)$ \\
\hline & $* * *$ & $* * *$ & $* * *$ \\
\hline \multirow{3}{*}{$L L A J_{i t}$} & 0,0291 & 0,0768 & 0,0798 \\
\hline & $(0,0000)$ & $(0,0000)$ & $(0,0000)$ \\
\hline & $* * *$ & $* * *$ & $* * *$ \\
\hline \multirow{3}{*}{$\triangle O P C_{i t}$} & 0,0012 & 0,0009 & 0,0012 \\
\hline & $(0,0034)$ & $(0,0436)$ & $(0,0071)$ \\
\hline & $* * *$ & $* *$ & $* * *$ \\
\hline \multirow{3}{*}{$P I B_{t}$} & 0,0038 & 0,0037 & \\
\hline & $(0,0000)$ & $(0,0000)$ & \\
\hline & $* * *$ & $* * *$ & \\
\hline \multirow{3}{*}{$\triangle L L A J$ neg } & 0,0004 & 0,0009 & 0,0006 \\
\hline & $(0,0000)$ & $(0,0000)$ & $(0,0000)$ \\
\hline & $* * *$ & $* * *$ & $* * *$ \\
\hline \multirow[b]{2}{*}{ LLAJneg } & $-0,0001$ & 0,0001 & 0,0002 \\
\hline & $(0,3429)$ & $(0,1112)$ & $(0,0158)$ \\
\hline $\mathrm{N}^{\mathrm{o}}$ de Entidades & 500 & 500 & 500 \\
\hline $\mathrm{N}^{\mathrm{o}}$ de Observações & 8470 & 8470 & 8470 \\
\hline Período & $2013 / 2017$ & $2013 / 2017$ & $2013 / 2017$ \\
\hline $\mathrm{R}^{2}$ & 0,0335 & 0,1010 & 0,1096 \\
\hline $\mathrm{R}^{2}$ Ajustado & 0,0329 & 0,0442 & 0,0515 \\
\hline Estatística F & 58,7978 & 1,7772 & 1,8861 \\
\hline F (p-valor) & 0,0000 & 0,0000 & 0,0000 \\
\hline
\end{tabular}

Onde: $\triangle$ PCLDd $_{\text {it: }}$ Variação da PLCD discricionária (modelo 3.2) da cooperativa $i$, considerando a diferença do momento $t$ e o período anterior, dividido pelo ativo total do período $t-1$. LLAJ it: lucro líquido ajustado antes da PCLD discricionária ( $\triangle \mathrm{PCLDd}_{\mathrm{i}} \mathrm{t}$ ) da cooperativa $i$, no momento $t$, dividido pelo ativo total do período $t$ - 1 . $\triangle \mathbf{O P C}_{\text {it: }}$ variação do estoque de operações de créditos da cooperativa $i$, considerando a diferença do momento $t$ e o período anterior, dividido pelo ativo total do período $t$ - 1 . PIBt: variação do Produtor Interno Bruto trimestral do país, no período $t$. LLAJ negit: variável dummy, assumindo valor 1 quando o lucro líquido antes da PCLD discricionária da cooperativa $i$, no período $t$, é negativo, e 0 para as demais. $\triangle \mathbf{L L A J}$ neg it: variável dummy, assumindo valor 1 quando o lucro líquido antes da PCLD discricionária da cooperativa $i$, no período $t$, variou negativamente em relação ao período anterior, e 0 para as demais. Nível de significância: ***1\%; **5\%; * $10 \%$. P-valores entre parênteses.

A análise dos resultados apresentados na Tabela 3 revela, em relação à variável de interesse $\left(\boldsymbol{L} \boldsymbol{L} \boldsymbol{A} \boldsymbol{J}_{i t}\right)$, que essa registra uma relação positiva e estatisticamente relevante com a variável dependente, representada pela PCLD discricionária do período ( $\triangle \boldsymbol{P C L D d}$ it). 
Evidenciando que quanto maior o lucro líquido do período, maior o valor reconhecido como PCLD discricionária, condição para caracterização da prática do gerenciamento de resultados.

Na literatura contábil a situação apresentada revela, conforme discutido na Seção 2 dessa pesquisa, que as cooperativas de crédito, assim como as instituições financeiras, tendem a suavizar os resultados. Ou seja, se em determinado exercício o lucro líquido ajustado $\left(\boldsymbol{L} \boldsymbol{L} \boldsymbol{A} \boldsymbol{J}_{i t}\right)$ aumentar, a PCLD discricionária $\left(\triangle \boldsymbol{P C} \boldsymbol{L D} \boldsymbol{d}_{i t}\right)$ também tende a aumentar.

Isso acontece, pois, quando o lucro líquido é maior, os gestores tendem a aumentar despesa proveniente dessa provisão discricionária, impactando negativamente no resultado, com isso o lucro líquido da cooperativa diminuirá colaborando pela constância no resultado. Caso contrário, em que o lucro líquido ajustado $\left(\boldsymbol{L} \boldsymbol{L} \boldsymbol{A} \boldsymbol{J}_{i t}\right)$ diminui no exercício, a PCLD discricionária $\left(\triangle \boldsymbol{P C L D d} \boldsymbol{d}_{i t}\right.$ ) tende a diminuir conforme os resultados expostos na Tabela 2. Dessa forma, os gestores das cooperativas de crédito utilizam a margem discricionária da provisão para aumentar o resultado, gerando novamente uma constância no lucro líquido do período.

Esse modelo é confirmado nas três estimações do modelo (3.3) - pooled, efeitos fixos seccionais e duplo efeitos fixos - o que se configura em elemento de robustez dos achados, corroborando a hipótese $\mathrm{H}_{1}$.

Em relação às variáveis de controle, cabe ressaltar, inicialmente, a associação positiva entre a variação do estoque das operações de crédito $\left(\triangle \boldsymbol{O P} \boldsymbol{C}_{i t}\right)$ com a variável representativa da PCLD discricionária ( $\left.\triangle \boldsymbol{P C} \boldsymbol{L} \boldsymbol{D} \boldsymbol{d}_{i t}\right)$. Logo, com o aumento das operações registradas, há um aumento do nível provisão da cooperativa de crédito no período, o que é um comportamento naturalmente esperado.

Além disso, percebe-se que quando a variável do PIB do país (PIBt) registra crescimento, também avança o comportamento da PCLD discricionária ( $\triangle \boldsymbol{P C L D d}$ it) no período. Esse resultado pode ser justificado, por exemplo, pelo fato de em momento de maior desenvolvimento econômico aumentar o estoque de crédito, o que pode refletir em maior nível de provisão.

$\mathrm{Na}$ análise das variáveis dummies do modelo, representativa do lucro líquido ajustado negativo (LLAJneg), assume valor 1 quando o lucro líquido antes da PCLD discricionária da cooperativa no período $t$, é negativo, e 0 caso contrário. Pelos resultados, verificou-se que o prejuízo ocorrido em determinado período, também impacta no nível de provisionamento realizados nessas instituições. Isso colabora para o aumento do lucro líquido e do 
reconhecimento da despesa, criando um colchão de suavização dos resultados. Com relação a variação negativa do lucro líquido em relação ao período anterior $\left(\Delta \boldsymbol{L} \boldsymbol{L A J} \boldsymbol{J} \boldsymbol{g}_{i t}\right)$, contatou-se que assumindo o valor 1 nos casos em que há um decrescimento do resultado, não há associação estatisticamente relevante de acordo com o modelo estudado.

Tendo em vista os resultados apresentados, infere-se que a cooperativas de crédito situadas no Brasil utilizam a PCLD discricionária como ferramenta para o gerenciamento de resultado. Esses resultados reforçam as evidências obtidas por Greenawalt e Sinkey (1988), Maia et al. (2013), Kanagaretnam et al. (2003), Zendersky (2005), Goulart (2007) e Bischoff (2014).

Sobre a relevância dos modelos, o coeficiente de determinação $\left(\mathrm{R}^{2}\right)$ apresentou que aproximadamente $3,2 \%$ da variação da variável dependente pode ser explicada, de acordo com teste de pooled, pelas variáveis independentes do modelo. No teste de efeitos fixos seccionais, a explicabilidade da variável dependente passou para $4,42 \%$, e no teste duplo efeitos fixos esse valor evidenciou que $5,15 \%$ também podem ser explicadas pelas variáveis independentes. Dessa forma, confirma-se de $\mathrm{H}_{1}$ tendo em vista que os resultados de todos os testes demonstram uma relação positiva e estatisticamente relevante apurada através do modelo (3.3). 


\section{CONSIDERAÇÕES FINAIS}

O presente estudo teve por objetivo identificar se as cooperativas de crédito no Brasil utilizam a PCLD discricionária como mecanismo para o gerenciamento de resultados. A literatura contábil, conforme discutido na Seção 2 desse estudo, apresenta diversos incentivos para os gestores gerenciarem resultados em instituições financeiras.

Dessa forma, as normas contábeis não alcançam todas as situações e, em alguns casos, permitem a possibilidade de escolha sobre como aplicar. A tendência da alta administração em demonstrar o crescimento almejado, bons índices de rentabilidade e lucratividade, prioriza a utilização da margem discricionária com foco nos incentivos próprios de participação dos resultados e etc.

A análise dos dados demostrou, primeiramente, que há associação positiva e estaticamente relevante entre a PLCD discricionária e o lucro líquido ajustado antes da provisão de clientes de crédito duvidoso. O modelo demonstrou ainda que outras variáveis de controle, tais como a variação do estoque das operações de crédito, o PIB do país, a variação negativa do resultado e o prejuízo da cooperativa de crédito em dado período, influenciam estatisticamente o comportamento da margem discricionária dessa provisão.

Os gestores procuram suavizar os resultados nas instituições financeiras, e assim realizam a reversão da despesa proveniente da provisão discricionária, impactando negativamente no resultado, para diminuir o lucro líquido da cooperativa e garantir a constância no resultado. Caso contrário, em que o resultado antes dos impostos e provisões diminui no exercício, a PCLD discricionária tende a diminuir, pois utiliza-se da margem arbitrária da provisão para aumentar o resultado, gerando novamente um resultado propício no período.

As limitações desse estudo resumem-se basicamente na falta de referencial teórico sobre as cooperativas de crédito no Brasil, tendo em vista que o SNCC representa um número pequeno com relação aos bancos. E, além disso, a falta de opções na busca de dados dessas instituições.

Por fim, sugere-se mais pesquisas acerca das cooperativas de crédito no mercado financeiro, tendo em vista o crescimento do número de associados e operações de crédito. Além disso, um estudo que aborde a utilização de títulos em TVM para o gerenciamento de resultados em cooperativas de crédito pode ser enriquecedor. 


\section{REFERÊNCIAS}

ALMEIDA, Sidimar Roberto Vieira. Estudo sobre a Implementação das Normas Internacionais de Contabilidade: O Setor de telecomunicações brasileiro. FOCO, Espírito Santo, V.8, $\mathrm{n}^{\mathrm{o}} 2$, Jan./jul. 2014.

ANNIBAL, C. A. Inadimplência do Setor Bancário Brasileiro: uma avaliação de suas medidas. Revista Banco Central do Brasil, Departamento de Estudos e Pesquisas (Depep). Brasília, 2009.

BANCO CENTRAL DO BRASIL. 50 maiores bancos e o consolidado do sistema financeiro nacional. Disponível em: < https://www3.bcb.gov.br/informes/relatorios>. Acesso em: 27 de ago. 2017.

BANCO CENTRAL DO BRASIL. Panorama do sistema nacional de crédito cooperativo. Dezembro de $2016 . \quad$ Disponível: <http://www.bcb.gov.br/pre/microFinancas/coopcar/pdf/panorama_de_cooperativas.pdf > Acesso em: 18 de

BRASIL. Lei n ${ }^{\circ}$ 4.595, de 31 de dezembro de 1964. Dispõe sobre a Política e as Instituições Monetárias, Bancárias e Creditícias, Cria o Conselho Monetário Nacional e dá outras providências. Disponível em: <http://www.planalto.gov.br/ccivil_03/leis/L4595.htm > Acesso em: 27 de ago. 2017.

BRASIL. Lei $\mathrm{n}^{\circ}$ 5.764, de 16 de dezembro de 1971. Define a Política Nacional de Cooperativismo, institui o regime jurídico das sociedades cooperativas, e dá outras providências. Disponível em: < http://www.planalto.gov.br/ccivil_03/leis/L5764.htm> Acesso em: 27 de ago. 2017.

BRASIL. Lei $\mathrm{n}^{\circ} 6.404$ de 15 de dezembro de 1976. Dispõe sobre as Sociedades por Ações. Disponível em: < http://www.planalto.gov.br/ccivil_03/leis/L6404consol.htm> Acesso em: 27 de ago. 2017.

BRASIL. Lei complementar $n^{\circ} 130$, de 17 de abril de 2009. Dispõe sobre o Sistema Nacional de Crédito Cooperativo e revoga dispositivos das Leis nos 4.595, de 31 de dezembro de 1964, e 5.764, de 16 de dezembro de 1971. Disponível em: <http://www.planalto.gov.br/ccivil_03/leis/LCP/Lcp130.htm> Acesso em: 27 de ago. 2017.

BISCHOFF, L.; LUSTOSA, P. R. B. PCLD e Suavização de Resultados em Instituições Financeiras no Brasil. XXXVIII Encontro ANPAD. Rio de Janeiro, 2014.

BROWN, Cristine; DAVIS, Kevin. Capital management in mutual financial institutions. Journal of Banking \& Finance, 2008.

BREWER, B. L.; ANGEL, R. J.; MAUTZ, R. David Jr. The Proliferation of "Special" Accounting Items: A Threat to Corporate Credibility. Souy Business Review; Fall Vol. 28(1), 2002. 
BALTAGI, B. Econometric analysis of panel data. John Wiley \& Sons, 2008.

COMITÊ DE PRONUNCIAMENTOS CONTÁBEIS - CPC 00 (R1), de 02 de dezembro de 2011. Estrutura Conceitual para Elaboração e Divulgação de Relatório Contábil-Financeiro. Brasília - DF. Disponível em: <http://www.cpc.org.br/CPC/DocumentosEmitidos/Pronunciamentos/Pronunciamento?Id=80>. Acesso em: 20 jul. 2017.

COMITÊ DE PRONUNCIAMENTOS CONTÁBEIS - CPC. Pronunciamento Técnico 39 - Instrumentos Financeiros: Apresentação. Disponível em: <http://www.cpc.org.br/CPC/DocumentosEmitidos/Pronunciamentos/Pronunciamento?Id=7> Acesso em: 10 de out. 2017.

CONFERÊNCIA I NTERNACIONAL DO TRABALHO - OIT, Recomendação n $^{\circ} 127$ de 21 de junho de 1966. Sobre o papel das cooperativas no progresso econômico e social dos países em via de desenvolvimento. Disponível em: < http://www.oitbrasil.org.br > Acesso em: 27 de jun. 2017.

CONSELHO FEDERAL DE CONTABILIDADE - CFC, Resolução CFC nº 1.203/09. Aprova a NBC TA 200 - Objetivos Gerais do Auditor Independente e a Condução da Auditoria em Conformidade com Normas de Auditoria. Brasília, 2009. Disponível em: < cfc.org.br/sisweb/sre/docs/RES_1203.doc> Acesso em: 21 de mai. 2017.

CONSELHO MONETÁRIO NACIONAL, Resolução No 2682 de 21 de dezembro de 1999. Dispõe sobre critérios de classificação das operações de crédito e regras para constituição de provisão para créditos de liquidação duvidosa. Disponível em: < www.bcb.gov.br/pre/normativos/res/1999/pdf/res_2682_v2_L.pdf> Aceso em: 02 de jul. 2011.

COLLINS, D.W.; KOTHARI S.P. An analisis of intertemporal and cross-sectional determinants of earnings response coefficients. Journal of Accounting and Economics, Vol. 11 (2-3), p. 143-182, 1989.

DAL-RI MURCIA, Fernando; NELSON CARVALHO, Luis. Conjecturas Acerca do Gerenciamento de Lucros, Republicação das Demonstrações Contábeis e Fraude

Contábil. Contabilidade. Vista \& Revista, vol. 18, núm. 4, octubre-diciembre, 2007, pp. 61Universidade Federal de Minas Gerais - Brasil.

DANTAS, J. A.; MEDEIROS, O. R.; LUSTOSA, B. P. R. O Papel de variáveis econômicas e atributos da carteira na estimação das provisões discricionárias para perdas em operações de crédito nos bancos brasileiros. BBR - Brazilian Business Review. FUCAPE Business School Vitoria, 2013.

DYE, R. A. Earnings management in an overlapping generation model. Journal of Accounting Research, Vol. 26(2), p. 195-235, 1988

EUROPEAN ASSOCIATION OF CO-OPERATIVE BANK (EACB), Characteristics of the co-operative banking model. Disponível em: < http://www.eacb.coop/en/cooperative- 
banks/definition-and-characteristics.html > Acesso em: 20 de jun. 2017.

FERREIRA, R. J. Contabilidade avançada e intermediária. Ed.: Ferreira, $3^{\circ}$ ed. Rio de Janeiro, 2010 .

GIL, Antônio Carlos. Como elaborar projetos de pesquisa. $4^{\circ}$ Ed. São Paulo: Atlas, 2002.

GREENAWALT, M. B., SINKEY, J.F., Jr. (1988). Bank loan loss provisioning and the income-smoothing hypothesis: An empirical analysis, 1976-1984. Journal of Financial Services Research, 1988.

GOULART, A. M. C. Gerenciamento de resultados contábeis em instituições financeiras no Brasil. Tese de Doutorado. Universidade de São Paulo, São Paulo, Brasil, 2007.

GUJARATI, D. N. Econometria básica. 4 ed. São Paulo: Campus, 2006.

HEALY, P. M. The Effect of Bonus Schemes on Accounting Decisions. Journal of Accounting and Economics, Vol. 7, p. 85-107. 1985

HENDRIKSEN, E. S. \& BREDA V. M. F. Teoria da Contabilidade. Tradução da $5^{\text {a edição }}$ americana por Antonio Z. Sanvicente. São Paulo: Atlas, 1999.

HILLIER, David; HODGSON, Allan; STEVENSON-CLARKE, Peta; LHAOPADCHAN, Suntharre. Accounting Window Dressing and Template Regulation: A Case Study of the Australian Credit Union Industry. Journal of Business Ethics, 2008.

IUDÍCIBUS, Sérgio de et al. Manual de contabilidade societária. São Paulo: Atlas, v. 792, p. $3,2010$.

IUDÍCIBUS, S.; MARION, J. S. Curso de Contabilidade para não contadores. $6^{\mathrm{a}}$. Ed. São Paulo: Atlas, 2009.

INTERNATIONAL ACCOUNTING STANDARDS BOARD (IASB). IFRS - Normas Internacionais de Relatório Financeiro, IBRACON, 2011.

KANAGARETNAM, K.; LOBO, G. J.; MATHIEU R. (2003). Managerial incentives for income smoothing through bank loan loss provision. Review of Quantitative Finance and Accounting 20 (1), 63-80.

MAIA, S. A.; BRESSAN, V. G. F.; LAMOUNIER, W. M.; BRAGA, M. J. Gerenciamento de resultados em cooperativas de crédito no Brasil. FUCAPE, 2013.

MACHADO, M. A. S.; KELLY, V. L. A. Gerenciamento de resultados em instituições financeiras No brasil: uma análise com base em provisões para crédito de liquidação duvidosa. Revista Evidenciação Contábil e Finanças. João Pessoa, 2016.

MARTINEZ, A. L. Gerenciamento" dos Resultados Contábeis: Estudo Empírico das 
Companhias Abertas Brasileiras. Tese (Doutorado em Contabilidade) - Faculdade de Economia, Administração e Contabilidade, Universidade de São Paulo. São Paulo, 2001.

MEINEN, E. M; PORT, M. Cooperativismo financeiro: percurso histórico, perspectivas e desafios. Ed.: Confebras, 2014.

MOHANRAN, P. S. How to Manage Earnings Management?. Accounting World - Institute of Chartered Financial Analysts of India, 2003.

NEGREIROS, H. S. Provisão para Crédito de Liquidação Duvidosa (PCLD) nas distribuidoras de Energia Elétrica. Universidade Federal do Rio Grande do Sul - UFRGS. Porto Alegre, 2013.

NIYAMA, J. K. Constituição da provisão para créditos de liquidação duvidosa de bancos e demais instituições financeiras - principais alterações introduzidas pelo conselho monetário nacional e o efeito nas demonstrações contábeis. v. 1, n. 1, Universidade Federal do Rio Grande do Sul. Porto Alegre, 2001.

NIYAMA, J. K.; GOMES, A. L. P. Contabilidade de instituições financeiras. Ed.: Atlas, $3^{\circ}$ ed. São Paulo, 2005.

ORGANIZAÇÃO DAS COOPERATIVAS BRASILEIRAS - OCB, Cooperativas de crédito e seus impactos 2010.2 Disponível em: <http://www.bcb.gov.br/pre/microFinancas/arquivos/horario_arquivos/trab_50.pdf >. Acesso em: 25 de mai. 2017.

ORGANIZAÇÃO INTERNACIONAL DO TRABALHO, Cooperativas: mudanças, oportunidades e desafios / editado Armand Pereira; em colaboração com Lucienne Freire e Lizzie Lagana - 1 ed. - Brasília : OIT, 2001.

PAULO, E. Manipulação das informações das informações contábeis: uma análise teórica e empírica sobre os modelos operacionais de detecção de gerenciamento de resultados, São Paulo, Tese (Doutorado) - Universidade de São Paulo, 2007.

PINHO, D. B.; PALHARES, V.M.A. O cooperativismo de crédito no Brasil do século XX ao XXI. Ed.: Confebras, v.2, 2010.

PRODANOV, Cleber Cristiano; FREITAS, Ernani Cesar de. Metodologia do trabalho científico [recurso eletrônico]: métodos e técnicas da pesquisa e do trabalho acadêmico. 2. Ed. Novo Hamburgo: Feevale, 2013.

RAUPP, Fabiano Maury; BAUREN, Ilse Maria. Como elaborar trabalhos monográficos em contabilidade: Teoria e Prática. $3^{\circ}$ Ed. São Paulo: Atlas, 2006.

SCHIPPER, K.. Commentary on earnings management. Accounting Horizons. Sarasota, Vol. 3, p. 91-102, December 1989.

SILVA, J. O.; BEZERRA, F. A. Análise do Gerenciamento de Resultados e o Rodízio de 
Firmas de Auditoria nas Empresas de Capital Aberto. Revista Brasileira de Gestão de Negócios, São Paulo, v. 12, n. 36, p. 304-321, jul./set. 2010.

ZENDERSKY, H. C. Gerenciamento de resultado em instituições financeiras no Brasil - 2000 a 2004. Dissertação de Mestrado, Programa Multiinstitucional e InterRegional de PósGraduação em Ciências Contábeis. Brasília, 2005. 


\section{ANEXOS}

Tabela 4: Relação de cooperativas de crédito que compõem a amostra do estudo

Seq. Nome das cooperativas de crédito

1 CC CREDICITRUS

2 CC VALE DO ITAJAÍ

3 SICOOB COCRED CC

4 CREDICOAMO

5 CC POUP E INV UNIÃO PARANÁ/SÃO PAULO

6 CECM FUNC INST FIN PUBL FED

7 CC POUPANÇA E INVESTIMENTO SICREDI PIONEIRA RS

8 CECM DOS MÉD DE MG LTDA.

9 CCPI OURO VERDE DO MATO GROSSO CC POUP INV VANGUARDA CATARATAS DO IGUAÇU E VALE DO

10 PARAÍBA

11 UNIPRIME NORTE DO PARANÁ

12 CCLA MAXI ALFA

13 CCPI DE CARLOS BARBOSA - SICREDI SERRANA RS

14 CCPI DA REGIÃO DOS VALES

15 CCLA SERRO AZUL

16 CC POUP E INV VALE DO PIQUIRI ABCD

17 CCLA CENTRO BRASILEIRA

18 CCPI SORRISO

19 CC UNICRED FLORIANÓPOLIS

20 CC POUP INV ASS CENTRO SUL MS

21 CCLA DO NORTE RS E OESTE SC

22 CC POUP INV CAMPOS GERAIS

23 CCLA LESTE CAPIXABA

24 CCLA REGIÃO DE GUARIBA

25 CCLA REGIÃO CENTRO DO RGS

26 CCLA SICOOB CREDICONAI

27 CCLA SÃO MIGUEL DO OESTE

28 CCLA DE ASSOCIADOS PLANALTO SICREDI PLANALTO RS/SC

29 SICREDI JOÃO PESSOA

30 SICOOB SUL-SERRANO

31 CCLA REGIÃO DE MARINGÁ

32 CCPI DO ARAGUAIA E XINGU

33 CCLA PAMPA GAÚCHO

34 CECM MÉD DE PORTO ALEGRE

35 CCPI DO SUDOESTE MT/PA

36 SICOOB SUL

37 CC POUP E INV OURO BRANCO ? SICREDI OURO BRANCO RS

38 CCLA DO LESTE DE SANTA CATARINA E DO PARANÁ 
CCLA SUDOESTE MG NORDESTE SP CCLA SUDOESTE GOIANO SICOOB NORTE CECM MÉD UNICRED SP CCLA ALTO URUGUAI CC POUP INV FRON PR, SC E SP - SICREDI FRONTEIRAS PR/SC/SP CC POUP INV NORTE MATO-GROSSENSE CCPI DE LAJEADO CCLA DE IBIRAIARAS SICOOB CENTRO-SERRANO CC POUP INV UNIÃO DOS EST MS, TO E OESTE DA BAHIA CCLA ALTOS DA SERRA CCPI DA ZONA SUL - SICREDI ZONA SUL RS CCLA ALTO URUGUAI CATARINENSE CCLA DO CENTRO SUL RONDONIENSE CCLA DO NORTE DO PARANÁ CCLA AGROEMPRESARIAL - SICREDI AGROEMPRESARIAL PR/SP CCPI CENTRO SERRA CCLA NOROESTE RS CCLA ASSOCIADOS ALIANÇA RS/SC CCLA DO VALE DO JURUENA SICOOB CREDISUL CCLA VALE DO CERRADO CCLA DE ASSOCIADOS REGIÃO DAS CULTURAS CCLA BOTUCARAÍ CCLA SUL CATARINENSE CC UNICRED SUL CATARINENSE LTDA CCPI DO VALE DO RIO PARDO SICREDI CEARÁ CENTRO NORTE CCLA DA REGIÃO DA PRODUÇÃO CCLAA ITAIPU SICOOB CREDITAIPU CCPI ALIANÇA CC POUP INV IGUAÇU - SICREDI IGUAÇU PR/SC/SP CCLA AURIVERDE CCM MED EMP MT CCLA INTEGRAÇÃO ROTA DAS TERRAS CECM UNICRED INTEGRAÇÃO CC UNICRED DESBRAVADORA CC POUP INV NOSSA TERRA - SICREDI NOSSA TERRA PR/SP CCLA CELEIRO CENTRO OESTE - SICREDI CCPI SUL RIOGRANDENSE CC SUL CCLA SUL DE MATO GROSSO 


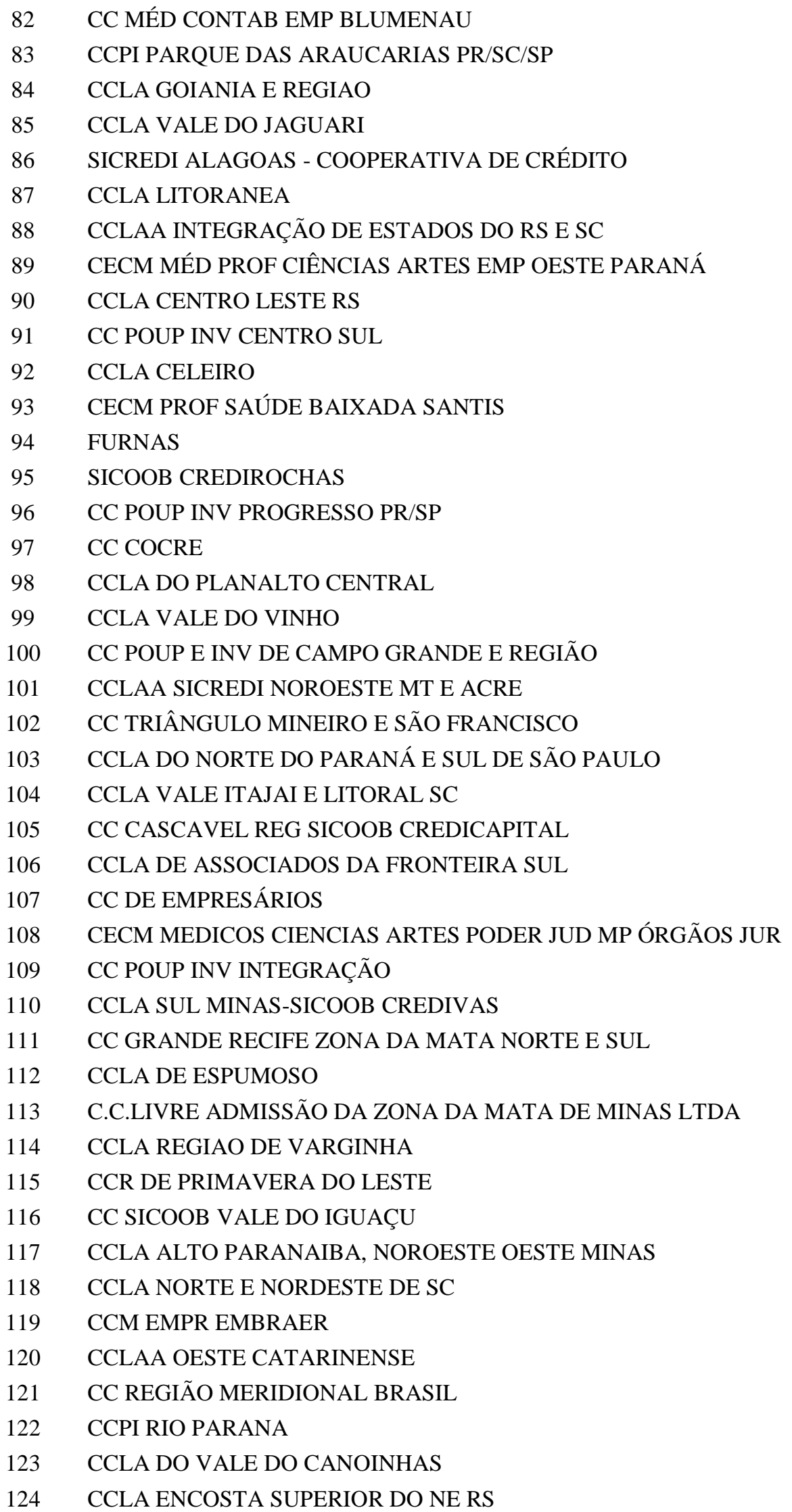




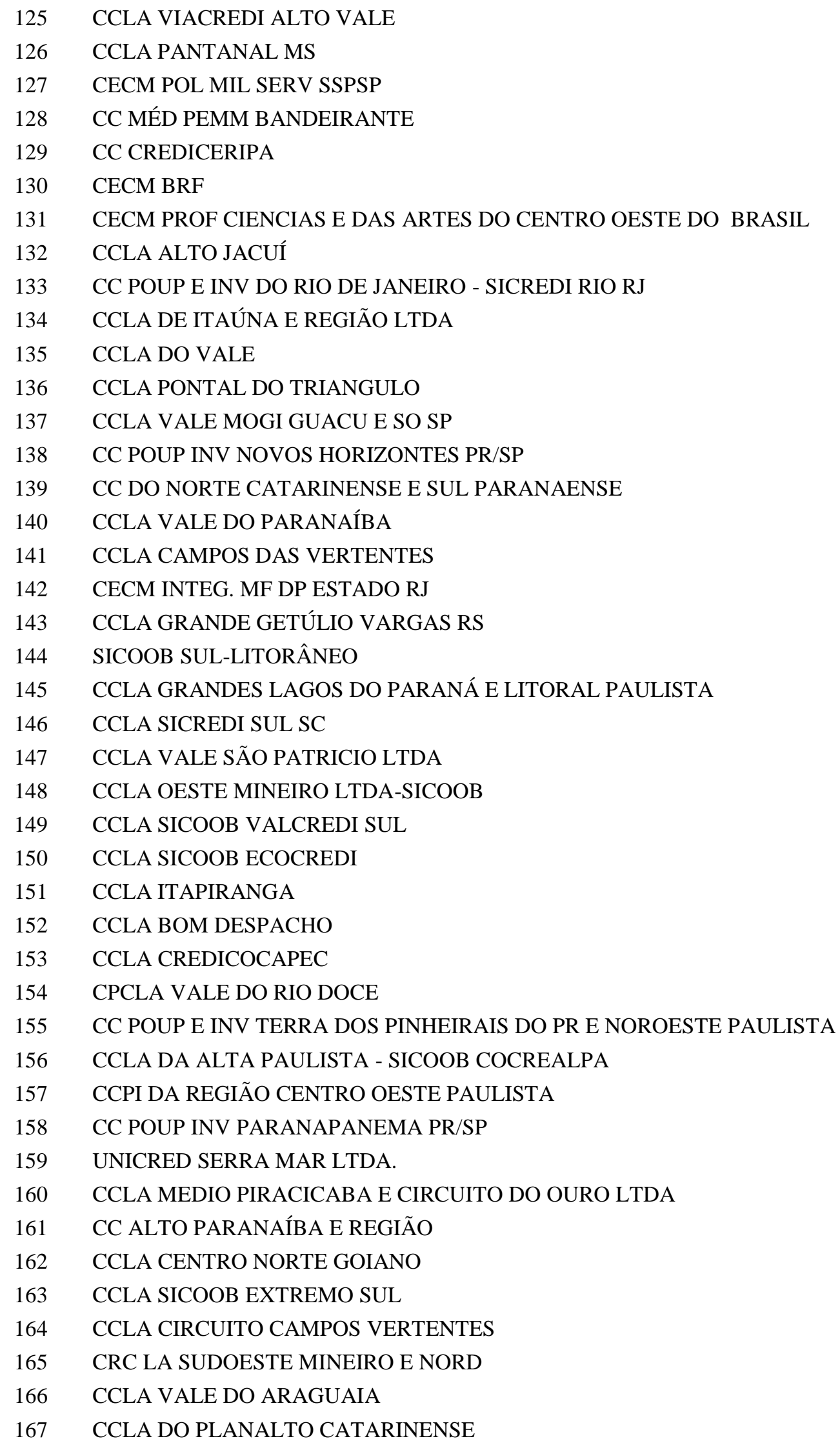




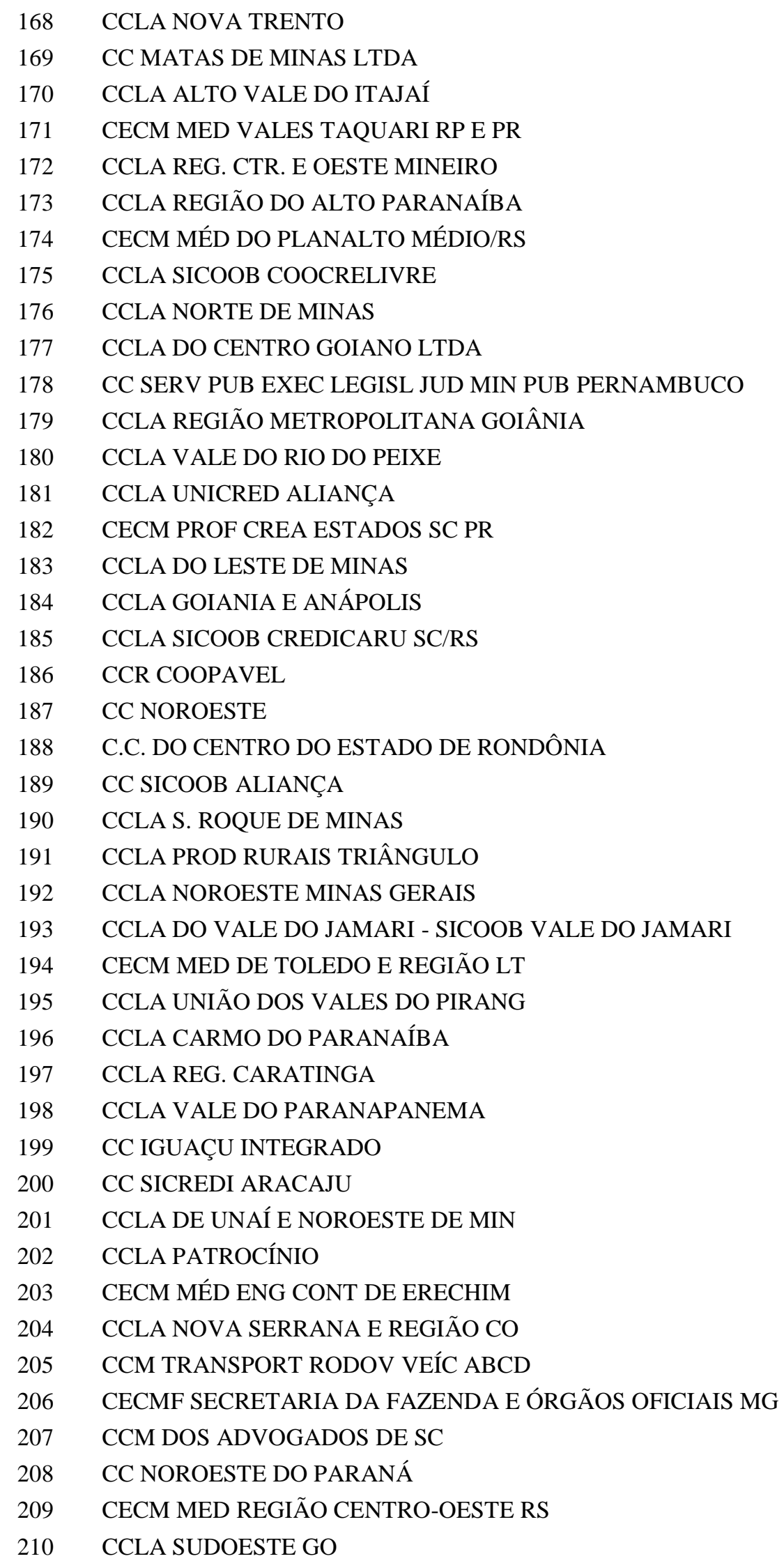


211 CECM SERV INST PUBL ENS SUP EST PB E DAS INST ORG PUBL DA PB

212 CC POUP INV VALOR SUSTENTÁVEL

213 CCLA DE ASSOCIADOS DA REGIÃO DE PALMEIRA DAS MISSÕES

214 CCLA DE SETE LAGOAS LTDA

215 CCLA DA REGIÃO DE PARÁ DE MINAS

216 CCLA ZONA DA MATA LTDA COOP DE CRÉDITO DE CAMPINA GRANDE - SICREDI CENTRO

217 PARAIBANA

218 CCLA DA REGIÃO DE ARAXÁ LTDA.

219 C.C.L.A. DO VALE DO MUCURI LTD

220 CCRPEMM REGIAO DE CAPIVARI

221 CCLA CAMPOS NOVOS

222 CCLA SANTO ANTONIO DO MONTE

223 CECM EMPR SERV EMPR SAN AMB SP

224 CCLA PARA DE MINAS

225 CCLA CONSELHEIRO PENA

226 CECM DOS PROFISSIONAIS DA SAUDE DA REG ALTA MOGIANA

227 CCLA DO VALE DO MACHADO - CREDISIS JICRED

228 CECM MAG MEM DO MP DE SC

229 CECM DOS JUIZES DO RS

230 CCLA DA BORBOREMA E AGR PARAIBANO E DOS SERV DO INSS NA PB

231 CECM MÉD DPS VALE DO PARAÍBA

232 CECM SERV MUN VALE PARAÍBA

233 CCR INT SOL DO PLANALTO SERRA

234 CC PODER JUD E MP MG

235 CCLA DO SUL E SUDOESTE DE MG, BAIXA MOGIANA E REGIÃO

236 CCR INT SOL DE CONSTANTINA

237 CREDIALIANÇA CCR

238 CCLA MEIO OESTE CATARINENSE

239 CCLA NORDESTE DE MINAS GERAIS

240 CCLA VALE DO AÇO

241 CCLA ITAÚNA

242 CECM MÉD MISSÕES E NOROESTE RS

243 CECMS JUST TRAB MPT NAC PJ FEDERAL MPU PA SC STM DF BOMB PA

244 CRESOL DE DOIS VIZINHOS

245 CCLA DA REGIÃO DE FRUTAL

246 CECM MÉD REG VALES SINOS E CAI

247 CCLA DE ARIQUEMES LTDA.

248 CCLA MATA MINEIRA

249 CCLA GOIÂNIA, SENADOR CANEDO

250 CCLA MONTE CARMELO

251 UNIPRIME

252 CC FORMIGA SICOOB CREDIFOR 
253 CCLA VALE MADEIRA MAMORÉ - SICOOB PORTOCREDI

254 CECM EMP TRANSPORTES DE SC RS

255 CC PROF SAÚDE Z MATA MINEIRA E SUL ES

256 CCPEMM DISTRITO FEDERAL

257 CCLA TRIÂNGULO MINEIRO E SUDESTE DE GOIÁS

258 CC INV DE ARARAQUARA E REGIÃO - SICREDI CENTRO NORTE SP

259 CCLA LAGOA DA PRATA

260 SICREDI BELEM

261 CCLA ALTO MEDIO JEQUITINHONHA

262 CCLA DO NORDESTE DO PA

263 CCLA TRÊS FRONTEIRAS

264 CCR INT SOL DE ERECHIM

265 CC DISTRITO FEDERAL E ENTORNO

266 CCR REG MOGIANA

267 CRESOL DE FRANCISCO BELTRAO

268 CECM SERV POD LEGIS MG

269 CCLA PARAÍSO DO TOCANTINS

270 CCLA REGIÃO DE UMUARAMA

271 CC CREDIMOTA

272 CCLA LESTE E NORDESTE MINEIRO

273 CCLA DE POMPEU LTDA.

274 CC MÉD SUL DE MINAS

275 CCLA REGIÃO DO ALTO SÃO FRANCISCO LTDA

276 CC PROF SAUDE TRIANGULO SUL MG

277 CC POUP INV INTEG MAGISTRAT MINISTÉRIO PÚBL PR

278 CECMEPEMM DAS REGIÕES SERRANAS E DO MEDIO PARAIBA

279 CC SERVIDOR FEDERAL

280 CCLA CAMPOS DA MANTIQUEIRA

281 CC POUP INV NOROESTE SP

282 CC DA FOZ DO RIO ITAJAÍ AÇU

283 CCR INT SOL UNIÃO DOS PINHAIS

284 CC SICREDI CENTRO PERNAMBUCANA

285 CECM SERV FEDCOM SESC SENAC SP

286 CC INTEG PODER JUD E INST JURID UNIAO EM MG

287 CC OESTE MINEIRO E RMBH

288 CCR INT SOL DE ÁGUAS MORNAS

289 CCLA SICOOB PERNAMBUCO

290 CCLA ALTO SÃO FRANCISCO

291 CCLA DA REGIÃO CENTRAL DE RONDÔNIA

292 CEC EMPR INST ENSINO E SERV PUB MG

293 CCLA REGIÃO DE TRÊS PONTAS

294 CCR GUARANI

295 CCLA REGIÃO ITURAMA 


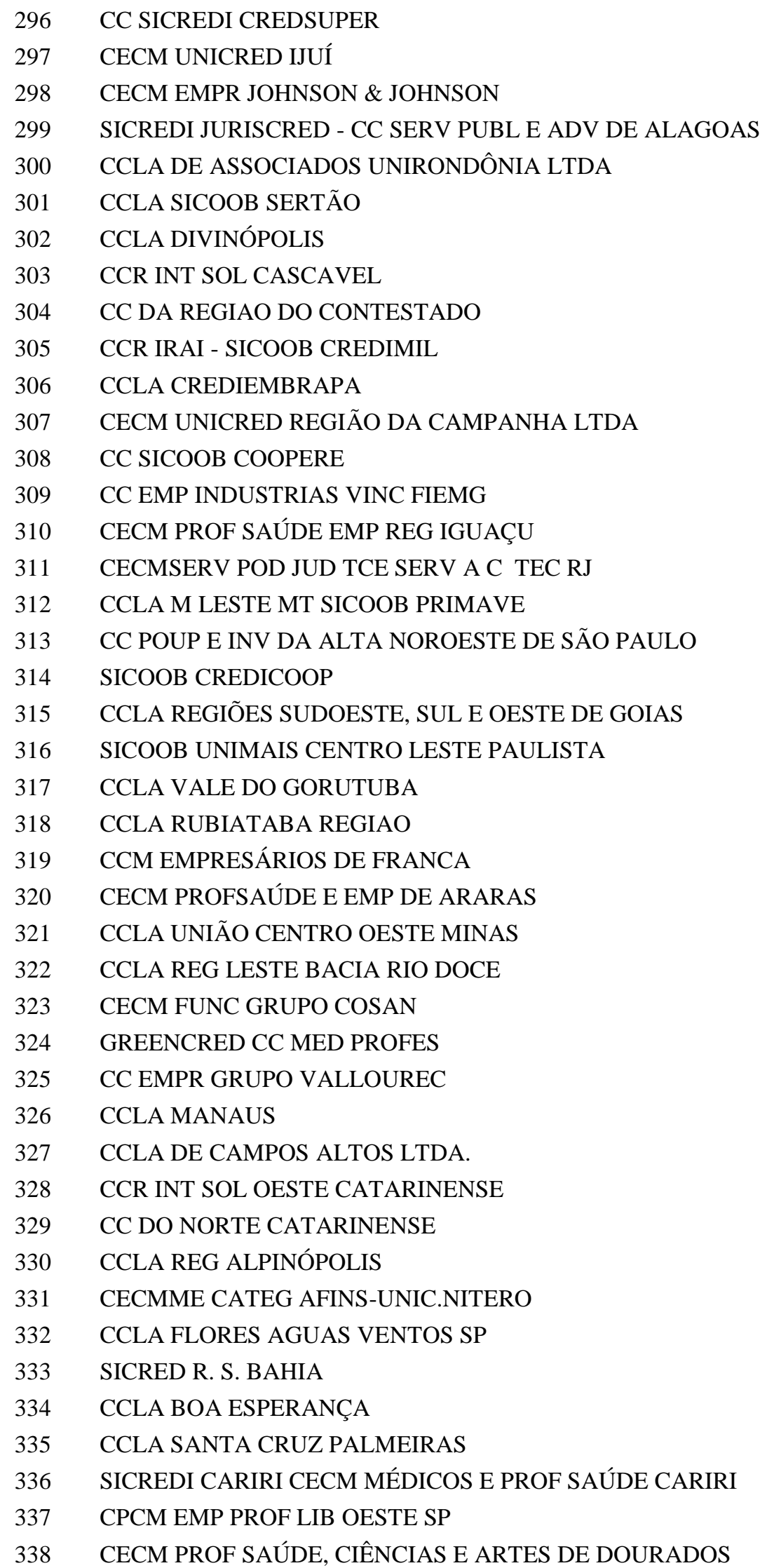


339 CECM PROF ÁREA NOTARIAL REGISTRAL

340 CCLA NORDESTE DE MG E SUL DA B

341 CECMS PODER JUDICIARIO EST. MT

342 CCLA CENTRO OESTE MINEIRO

343 CC VALE ITAJAÍ E ITAPOCÚ

344 CECM PROF TECN ENG ARQ BH RMBH

345 CCLA CENTRO-SUL GOIANO

346 CCLA CENTRO NORDESTE MINEIRO

347 CCLA DO CENTRO LESTE DE RONDÔNIA LTDA

348 CECMS PJ ENSINO SUPERIOR ADVOGADOS DEFENSORES PUBLICOS

349 CCLA URUBICI

350 CCLA DE PARAOPEBA

351 CCR DE ABELARDO LUZ

352 CRESOL DE ITAPEJARA D`OESTE

353 CCLA CAMPINA VERDE

354 CC EMPR DO SISTEMA FIESC

355 CC NOSSA SENHORA DO DESTERRO

356 CRESOL DE CRUZ MACHADO

357 CCR INT SOL DE SANTO CRISTO

358 CECM MÉD JUIZ DE FORA

359 CCLA DE LUZ - SICOOB CREDILUZ

360 CECM ADVOGADOS DE GOIÁS

361 CCR INT SOL DE TENENTE PORTELA

362 CRESOL CHOPINZINHO

363 CECM SERV EXEC FED SECSAÚDE DF

364 CCLA BAMBUÍ

365 CC JUST GOIAS E CELG

366 CECM MAGISTRADOS DE SÃO PAULO

367 CECM MÉD SUDESTE PAULISTA LTDA

368 CC INTEGRANTES MIN PUBL E PODER JUDIC AP E CE E CCLA PA

369 CCLA PEDRO LEOPOLDO

370 CCR PROD AGR PEC MD SOROCABANA

371 CCR INT SOL DO VALE EUROPEU

372 CCLA DE GOIÂNIA E MICRORREGIÕE

373 CCLA REGIÃO DE CAMPO BELO

374 SICOOB FLUMINENSE

375 CCLA CENTRO OESTE GOIANO LTDA.

376 CC REG SUDOESTE PR

377 CCM EMPR MAXION

378 CCLA DO PLANALTO SERRANO

379 CECM TRAB DO GRUPO SÃO MARTINHO USICRED

380 CC VALE DO SÃO FRANCISCO - SICREDI VALE DO SÃO FRANCISCO

381 CRESOL DE VERE 


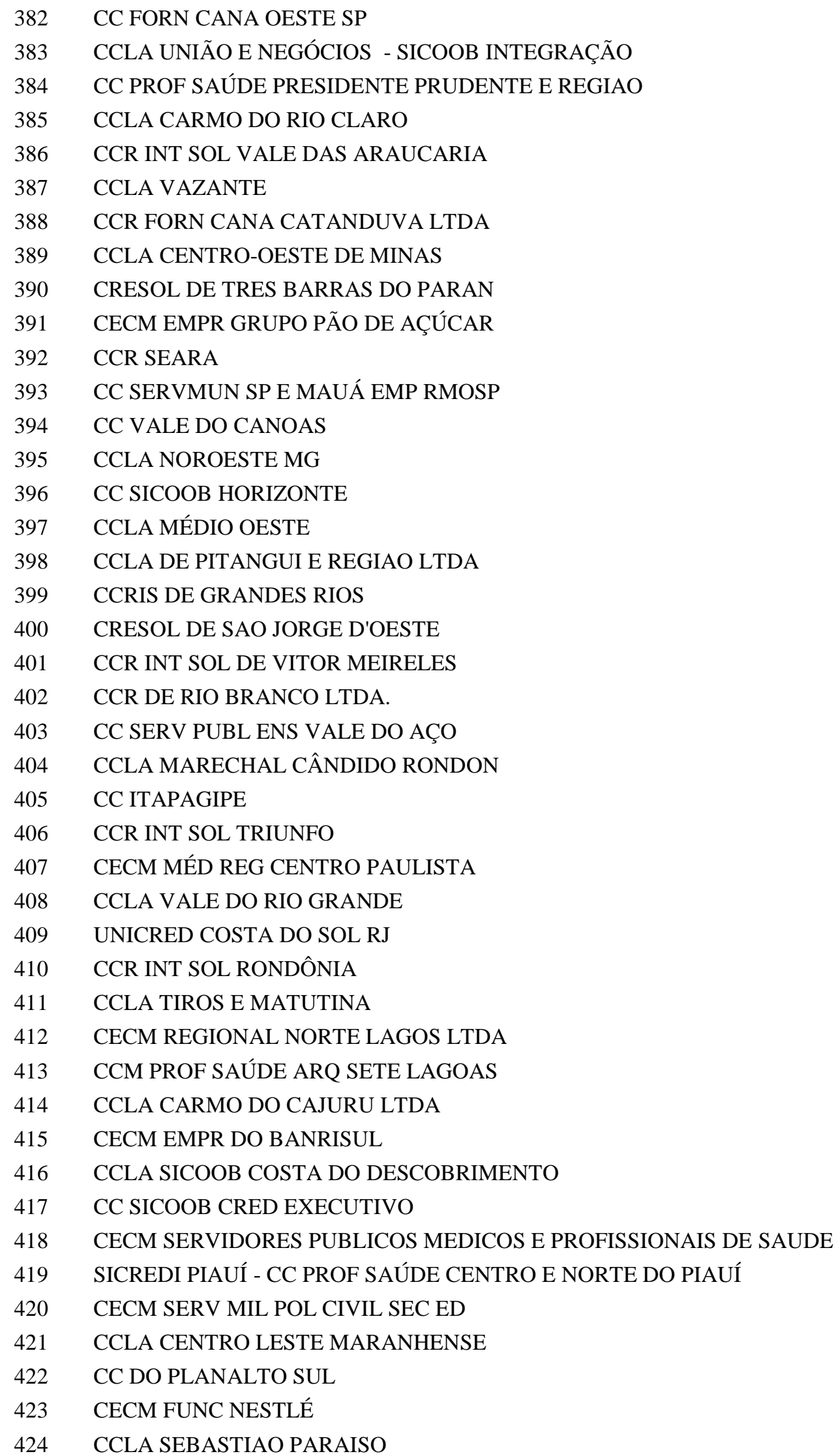




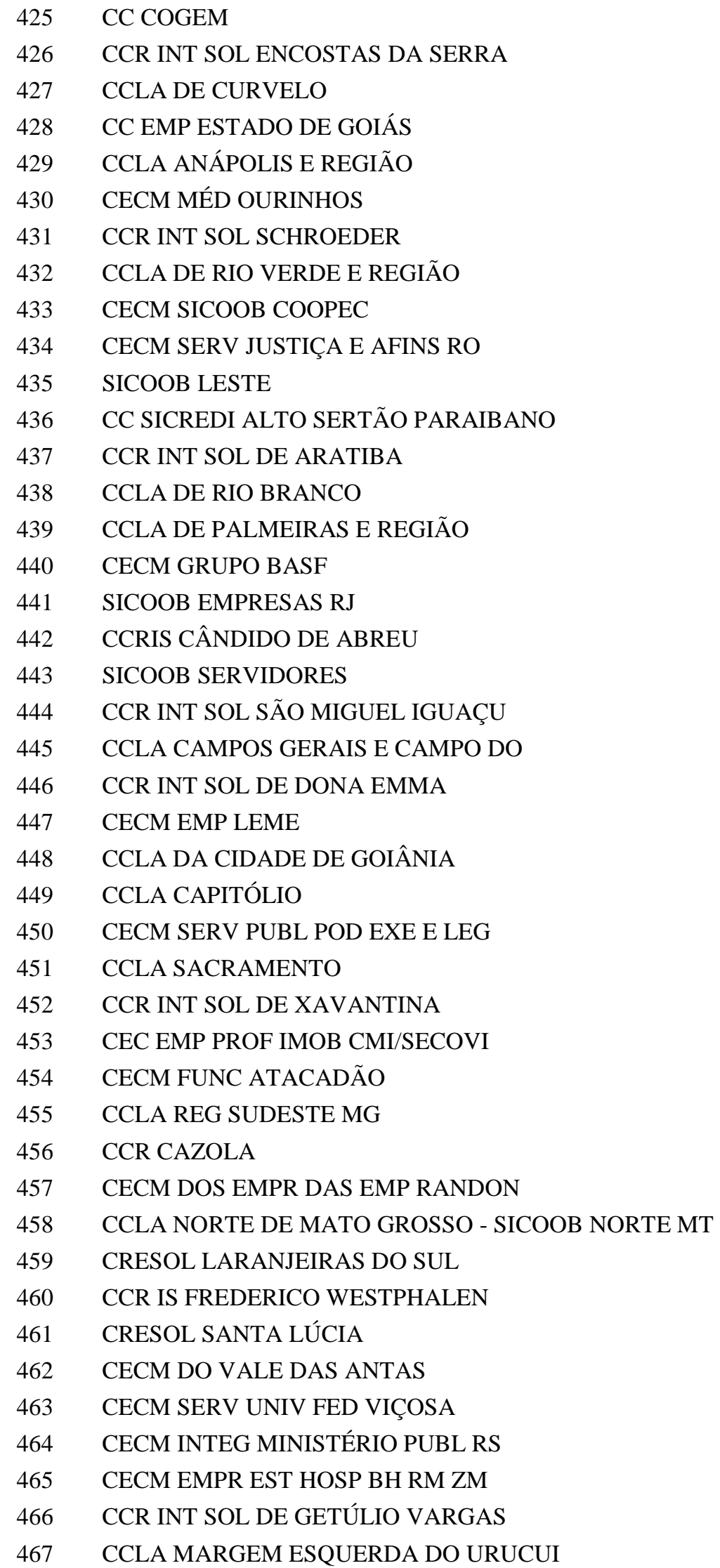


468 C.C. CAPITAL FORTE - SICOOB CREDIFORTE

469 CCLA LESTE MINEIRO

470 CRESOL MARMELEIRO

471 CCLA DE GUARAMIRIM

472 CECM DOS INTEGRANTES DA BM

473 CC LA IGUATAMA

474 CRESOL DE IBEMA

475 CC EMP. DA GRANDE DOURADOS

476 CCR INT SOL DE CURITIBANOS

477 CECM MÉD EMP CRUZ ALTA

478 CCR INT SOL DE ITUPORANGA

479 CCLA MONTES CLAROS

480 CCLA ESMERALDAS - SICOOB CREDIESMERALDAS

481 CCR INT SOL DE JACUTINGA

482 CCLA DO OESTE MARANHENSE - SICOOB OESTE MARANHENSE

483 CCLA SICOOB CREDICONQUISTA

484 CCLA CERES E RIALMA LTDA

485 CCLA REGIAO SUL DE MATO GROSSO

486 CCR SÃO VICENTE MINAS

487 CCLA DO SUL CATARINENSE

488 CECM SERV PUBL SÃO PAULO

489 CECM SERV MUN S JOAO BOA VISTA

490 CECM DOS MILITARES EST DE SC

491 CC SICREDI MOSSORÓ

492 CCM DESP TRÂNS SC E RS

493 CCLA SICOOB NORTE SUL

494 CECM MÉD JOAÇABA

495 CRESOL DE NOVA PRATA DO IGUACU

496 CCR SICOOB COOPEMAR

497 CECM EMPREG DA MONDELEZ BRASIL PHILIP MORRIS E K\&S ALIMENTOS

498 CCLA DE ITAJUBÁ - SICOOB SUL

499 CCLA DE CAÇADOR

500 CCR INT SOL GUARANI MISSÕES 